Check for updates

Cite this: RSC Adv., 2019, 9, 6363

\title{
Facile synthesis of highly conductive PEDOT:PSS via surfactant templates
}

\author{
Phimchanok Sakunpongpitiporn, ${ }^{a}$ Katesara Phasuksom, ${ }^{a}$ Nophawan Paradee ${ }^{b}$ \\ and Anuvat Sirivat (iD *a
}

Poly(3,4-ethylenedioxythiophene):poly(styrenesulfonate) (PEDOT:PSS) nanoparticles in powder form with high electrical conductivity were synthesized via chemical oxidative polymerization. In addition, the effects of EDOT : PSS weight ratio, EDOT : $\mathrm{Na}_{2} \mathrm{~S}_{2} \mathrm{O}_{8}$ mole ratio, and surfactant concentration and type, namely hexadecyltrimethylammonium bromide (CTAB), sodium dodecylsulfate (SDS), and polyoxyethylene octyl phenyl ether (Triton X-100) on the properties of PEDOT:PSS were investigated. For the effect of EDOT : PSS weight ratio, at the EDOT : $\mathrm{Na}_{2} \mathrm{~S}_{2} \mathrm{O}_{8}$ mole ratio of $1: 1$, the EDOT : PSS weight ratio of 1 : 11 was the optimal condition to obtain electrical conductivity of $999.74 \pm 10.86 \mathrm{~S} \mathrm{~cm}^{-1}$ due to the high amount of PSS ${ }^{-}$and $\mathrm{SO}_{4}{ }^{2-}$ available to interact with the PEDOT chain with a low \% PSSNa. For the effect of EDOT: $\mathrm{Na}_{2} \mathrm{~S}_{2} \mathrm{O}_{8}$ mole ratio, at the EDOT:PSS weight ratio of $1: 11$, the EDOT : $\mathrm{Na}_{2} \mathrm{~S}_{2} \mathrm{O}_{8}$ mole ratio of $1: 2$ was the best condition as it provided the highest dopant (PSS ${ }^{-}$and $\mathrm{SO}_{4}{ }^{2-}$ ) amount, while the \% PSSNa was relatively low. For the effect of surfactant type and concentration, at the EDOT : PSS weight ratio of $1: 11$ and EDOT : $\mathrm{Na}_{2} \mathrm{~S}_{2} \mathrm{O}_{8}$ mole ratio of $1: 2$, Triton $\mathrm{X}$ 100 at 2.5CMC provided electrical conductivity higher than with CTAB and SDS. The thermal stability of PEDOT:PSS obtained from various conditions was investigated, and PEDOT:PSS without surfactant showed the highest thermal stability since it produced the highest char yield. In this study, the highest electrical conductivity of PEDOT:PSS, which was obtained in the presence of Triton X-100 to reduce the PSSNa amount, was $1879.49 \pm 13.87 \mathrm{~S} \mathrm{~cm}^{-1}$, the highest value reported to date.

Received 24th October 2018 Accepted 6th February 2019

DOI: $10.1039 / c 8 r a 08801 b$

rsc.li/rsc-advances transistors, ${ }^{8}$ actuators, ${ }^{9}$ anti-static coatings, sensors, batteries, solar cells, ${ }^{10}$ and drug delivery. ${ }^{11}$

Poly(3,4-ethylenedioxythiophene) (PEDOT) is one of most studied conductive polymers owing to its relatively high electrical conductivity and electro-optical properties. PEDOT can be synthesized via both chemical oxidative polymerization and electrochemical polymerization. However, chemical oxidative polymerization provides a higher yield with no special setup required. ${ }^{12}$ Although PEDOT has high electrical conductivity, it is insoluble in water, making it difficult to process. This problem is overcome by using a polyelectrolyte, poly(styrenesulfonic acid) (PSS), which acts as a dopant and stabilizer for PEDOT through charge balance. ${ }^{13}$

Poly(3,4-ethylenedioxythiophene):poly(styrenesulfonate)

(PEDOT:PSS) is a PEDOT derivative, which has higher electrical conductivity as compared to other CPs. ${ }^{14}$ Moreover, it has other useful properties, such as high transparency, ${ }^{15}$ low thermal conductivity, low density, good flexibility, and high thermal stability. ${ }^{16}$ In general, PEDOT:PSS is used in various electrical and optical devices, such as thin film transistors, light-emitting diodes, sensors, and photovoltaics. ${ }^{17}$

The electrical conductivity of PEDOT:PSS can be enhanced by solvent treatment, ${ }^{18}$ adding surfactant, ${ }^{19}$ and varying the PSS concentration. ${ }^{20}$ Ouyang et al. investigated the effect of organic
${ }^{a}$ The Conductive and Electroactive Polymers Research Unit, The Petroleum and Petrochemical College, Chulalongkorn University, Bangkok 10330, Thailand. E-mail: anuvat.s@chula.ac.th

${ }^{b}$ Department of Chemistry, Faculty of Science, King Mongkut's University of Technology Thonburi, Bangkok, 10140, Thailand 
solvent treatment using secondary dopants, such as acetonitrile (ACN), 4-methoxyphenol, $\mathrm{N}, \mathrm{N}$-dimethylacetamide (DMAc), $\mathrm{N}$ methyl-2-pyrrolidone (NMP), ethylene glycol (EG), and dimethyl sulfoxide (DMSO) to increase the electrical conductivity of the PEDOT:PSS film. The highest electrical conductivity of a PEDOT:PSS film treated with DMSO was $200 \mathrm{~S} \mathrm{~cm}^{-1} \cdot{ }^{18} \mathrm{Oh}$ et al. studied the effect of Triton X-100 (nonionic surfactant) on the electrical conductivity of PEDOT:PSS films, which increased from $0.85 \pm 0.08$ to $882 \pm 75 \mathrm{~S} \mathrm{~cm}^{-1}$ at a Triton X-100 concentration of $1.0 \mathrm{wt} \%{ }^{19}$ Horri et al. studied the effect of EDOT : PSS weight ratio on the electrical conductivity of PEDOT:PSS films, and an EDOT : PSS weight ratio of $1: 2.3$ provided the highest electrical conductivity of $700 \mathrm{~S} \mathrm{~cm}^{-1} .^{20}$

Alternatively, PEDOT:PSS can be prepared in powder form, which can be subsequently modified and processed for various applications, such as proton exchange membrane fuel cells, ${ }^{21}$ actuators, ${ }^{22}$ and sensors. ${ }^{23}$ Lefebvre et al. studied the effect of the PEDOT:PSS weight ratio in the range of $1: 2.5$ to $1: 7.5$, where the electrical conductivity of the PEDOT:PSS powder varied from 0.3 to $1.3 \mathrm{~S} \mathrm{~cm}^{-1} \cdot{ }^{24}$ Wichaiansee $e t$ al. synthesized PEDOT:PSS powder via chemical oxidative polymerization at room temperature using sodium persulfate $\left(\mathrm{Na}_{2} \mathrm{~S}_{2} \mathrm{O}_{8}\right)$ as the oxidizing agent and ferric sulphate $\left(\mathrm{Fe}_{2}\left(\mathrm{SO}_{4}\right)_{3}\right)$ as the catalyst. The synthesized PEDOT:PSS powder possessed electrical conductivity of $27.5 \pm$ $0.6 \mathrm{~S} \mathrm{~cm}^{-1} \cdot{ }^{22}$ Chanthanont et al. synthesized PEDOT:PSS powder using $\mathrm{Na}_{2} \mathrm{~S}_{2} \mathrm{O}_{8}$ as the oxidizing agent and $\mathrm{Fe}_{2}\left(\mathrm{SO}_{4}\right)_{3}$ as the catalyst in aqueous solution at room temperature, and the electrical conductivity of the PEDOT:PSS powder was determined to be $11.69 \pm 0.006 \mathrm{~S} \mathrm{~cm}^{-1} \cdot{ }^{23}$ In summary, it can be noted that PEDOT:PSS in the powder form has relatively lower electrical conductivity than that of its films, as previously reported.

Herein, we report the synthesis of PEDOT:PSS nanoparticles with high electrical conductivity via chemical oxidative polymerization in aqueous solution at room temperature. The effects of the EDOT : PSS weight ratio, EDOT : $\mathrm{Na}_{2} \mathrm{~S}_{2} \mathrm{O}_{8}$ mole ratio, and surfactant type and concentration on the properties of PEDOT:PSS were systematically investigated. The PEDOT:PSS powder samples were characterized via Fourier transform infrared spectroscopy (FT-IR), Raman spectroscopy (Raman), and wide-angle X-ray spectroscopy (XRD) to determine their chemical structure, X-ray photoelectron spectroscopy (XPS) to analyze their element contents, UV-Vis spectrophotometry (UV-Vis) to determine their doping state, and field-emission scanning electron microscopy (FE-SEM) to determine their particle shape and size. Thermogravimetric analysis (TG-DTA) was used to determine their thermal stability. It was found that the PEDOT:PSS powder with the EDOT : PSS weight ratio of $1: 11$, EDOT : $\mathrm{Na}_{2} \mathrm{~S}_{2} \mathrm{O}_{8}$ mole ratio of $1: 2$, and Triton $\mathrm{X}-100$ at the concentration of 2.5CMC possessed the highest electrical conductivity of $1879.49 \pm$ $13.87 \mathrm{~S} \mathrm{~cm}^{-1}$ with the corresponding spherical particle size of $56.77 \pm 5.54 \mathrm{~nm}$, values not previously obtained to date.

\section{Experimental}

\subsection{Materials}

3,4-Ethylenedioxythiophene (EDOT, 97\% purity) monomer, poly(styrenesulfonate) (PSS, 99\% purity) with $M_{\mathrm{w}}$ of $75000 \mathrm{~g}$ $\mathrm{mol}^{-1}$, hexadecyltrimethylammonium bromide (CTAB, $\geq 96 \%$ purity), and sodium persulfate $\left(\mathrm{Na}_{2} \mathrm{~S}_{2} \mathrm{O}_{8}, \geq 98 \%\right.$ purity) were purchased from Sigma Aldrich. Sodium dodecylsulfate (SDS, $\geq 99 \%$ purity) and polyoxyethylene octyl phenyl ether (Triton X$100, \geq 99 \%$ purity) were purchased from Omnipur. Methanol (>99.8\% purity) and acetone (99.5\% purity) were purchased from RCI Labscan. Distillated water was used as the solvent in the synthesis. All reagents were of analytical reagent grade.

\subsection{Synthesis of PEDOT:PSS}

To investigate the effect of the EDOT : PSS weight ratio, $0.5 \mathrm{~g}$ of EDOT was mixed with PSS ranging from $0.5 \mathrm{~g}$ to $6.5 \mathrm{~g}$ (weight ratios of 1-13), where the $\mathrm{Na}_{2} \mathrm{~S}_{2} \mathrm{O}_{8}$ content as the oxidant was fixed at $0.8335 \mathrm{~g}$ to give the EDOT : $\mathrm{Na}_{2} \mathrm{~S}_{2} \mathrm{O}_{8}$ mole ratio of $1: 1$. The ingredients were dissolved in $100 \mathrm{~mL}$ of DI water, then the solution was stirred for $24 \mathrm{~h}$ at room temperature. The precipitate was collected by centrifugation at $9000 \mathrm{rpm}$, rinsed with a mixed solution of acetone : methanol with a volume ratio of $3: 20,{ }^{25}$ and then dried in an oven at $60{ }^{\circ} \mathrm{C}$ for $24 \mathrm{~h}$.

To determine the effect of the EDOT : $\mathrm{Na}_{2} \mathrm{~S}_{2} \mathrm{O}_{8}$ mole ratio, the synthesis procedure was the same as before. $0.83,1.25,1.67$, $2.08,2.50$, and $3.33 \mathrm{~g}$ of $\mathrm{Na}_{2} \mathrm{~S}_{2} \mathrm{O}_{8}$ were added to $0.5 \mathrm{~g}$ of EDOT to give the EDOT $: \mathrm{Na}_{2} \mathrm{~S}_{2} \mathrm{O}_{8}$ mole ratios of $1: 1,1: 1.5,1: 2,1: 2.5$, $1: 3,1: 4$, and the EDOT : PSS weight ratio was fixed at $1: 11$ (0.5 g : $5.5 \mathrm{~g})$.

To study the effect of surfactant type, namely CTAB, SDS, and Triton X-100, and concentration, each surfactant (0.084 g, $0.721 \mathrm{~g}, 0.141 \mathrm{~g}$, respectively) was added to $100 \mathrm{~mL}$ of distilled water and stirred for $1 \mathrm{~h}$ to from a surfactant solution at 2.5CMC. Then $0.5 \mathrm{~g}$ of EDOT was added in the surfactant solution, which was continuously stirred for $1 \mathrm{~h}$. Then PSS ( $5.5 \mathrm{~g}$ ) was added to the above solution, and it was stirred for $1 \mathrm{~h}$ before the $\mathrm{Na}_{2} \mathrm{~S}_{2} \mathrm{O}_{8}$ oxidant (1.67 g) was added. The EDOT : PSS weight ratio was fixed at $1: 11$ and the EDOT $: \mathrm{Na}_{2} \mathrm{~S}_{2} \mathrm{O}_{8}$ mole ratio was $1: 2$. The solution was stirred continuously for $24 \mathrm{~h}$ at room temperature, and the color of the solution changed from clear to dark blue. The precipitate was centrifuged at $9000 \mathrm{rpm}$ and then washed with a solution of acetone : methanol at the volume ratio of $3: 20$. Finally, the precipitate was dried in an oven at $60{ }^{\circ} \mathrm{C}$ for $24 \mathrm{~h}$. Next, the PEDOT:PSS precipitate was ground in a mortar by hand for 3 min to obtain the PEDOT:PSS powder with smaller particle sizes, which was further modified for characterization. ${ }^{26}$ Lislie et al. reported that grinding PPy with a mortar and pestle for 10 min did not significantly change its electrical conductivity. ${ }^{26}$ However, Fufang et al. reported that the electrical conductivity of PPy decreased by $21 \%$ and the particle size decreased by $26 \%$ after grinding in a mortar for $1 \mathrm{~h}^{27}$

\subsection{Characterization of PEDOT:PSS nanoparticles}

The critical micelle concentration (CMC) of PSS was determined by measuring its surface tension using a tensiometer (Kruss/ Easydyne tensiometer, K20) with the Wilhelmy plate mode at $23{ }^{\circ} \mathrm{C}$. PSS was dissolved in deionized water at various EDOT : PSS weight ratios. The CMC of PSS was found to be $7 \times$ $10^{-5} \mathrm{~mol} \mathrm{~L}^{-1}$. 
The functional group analysis was carried out via Fourier transformed infrared spectroscopy, FTIR (Thermo Nicolet, Nexus 670). All spectra were recorded in the wavenumber range of $400-4000 \mathrm{~cm}^{-1}$, with 32 scans and a resolution of $4 \mathrm{~cm}^{-1}$. The PEDOT:PSS samples were mixed with background $\mathrm{KBr}$ powder and compressed using a hydraulic press machine.

The chemical and structural information of the PEDOT:PSS powder were identified via Raman spectroscopy (Bruker, Ram II) with a laser source at $1064 \mathrm{~nm}$ and power of $22 \mathrm{~mW}$. All spectra were recorded in the wavenumber range of $400-$ $4000 \mathrm{~cm}^{-1}$, with 800 scans and a resolution of $4 \mathrm{~cm}^{-1}$.

The PEDOT:PSS crystalline structure was identified via wideangle X-ray spectroscopy, XRD (Rigaku/Smartlab), at a scan step of $0.02^{\circ}$ and scan speed of $5^{\circ} \mathrm{min}^{-1}$ in the $2 \theta$ range of $5^{\circ}$ to $70^{\circ}$. The $\mathrm{Cu}-\mathrm{K}_{\alpha}$ radiation source was operated at $40 \mathrm{kV} / 30 \mathrm{~mA}$. The PDLX 2 software was used to analyze the PEDOT:PSS XRD patterns.

The element analysis was carried out via X-ray photoelectron spectroscopy, XPS (Kratos, Axis Ultra DLD), using a monochromatized $\mathrm{Al} \mathrm{K}_{\alpha}$ radiation source and recorded at the analyzer pass energy of $160 \mathrm{eV}$ for the survey scan, and at $40 \mathrm{eV}$ for the high-resolution scan. All spectra were corrected by using the reference C 1s (binding energy of $284.8 \mathrm{eV}$ ). The Casa-XPS software was used for the interpretation of the XPS spectra.

The doping state and optical band gap of PEDOT:PSS was identified via UV-Vis spectrophotometry, UV-Vis (Tecan, The Infinite ${ }^{\circledR} 200$ PRO NanoQuant). The PEDOT:PSS powders were dissolved in deionized water and filtered using a nylon filter. Deionized water was used as the reference. The i-Control software was used to determine the UV adsorption of the PEDOT:PSS solutions. The band gap energy was calculated using the Tauc eqn (1): ${ }^{28}$

$$
\alpha h \nu=A\left(h \nu-E_{\mathrm{g}}\right)^{n}
$$

where $\alpha$ is the adsorption coefficient, $h v$ is the photon energy $(\mathrm{eV}), h$ is Plank's constant, $v$ is the frequency $\left(\mathrm{s}^{-1}\right), A$ is a constant, $E_{\mathrm{g}}$ is the band gap energy (eV), and $n$ is equal to 0.5 for direct transitions. The adsorption coefficient $(\alpha)$ was calculated from the Beer-Lambert's relation (2): ${ }^{29}$

$$
\alpha=2.303 \mathrm{Ab} / I
$$

where, $\mathrm{Ab}$ is the absorbance and $I$ is the sample path length. The extrapolation of the linear line from the plot between $(\alpha h \nu)^{2}$ on the $y$ axis and $h \nu$ on the $x$ axis gives $E_{\mathrm{g}}$.

The morphology of PEDOT:PSS was identified via fieldemission scanning electron microscopy, FE-SEM (Hitachi, S4800), operating at $5 \mathrm{kV} / 10 \mu \mathrm{A}$ at a magnification of 100000 . Each sample was distributed on the sample holder with a carbon adhesive tape and coated with a thin layer of platinum before the measurement.

The thermal analysis was carried out using a thermogravimetric analyzer, TG-DTA (Perkin Elmer, TGA model 7). 4 to $8 \mathrm{mg}$ of each sample was loaded into an aluminum pan. The sample was scanned from $30{ }^{\circ} \mathrm{C}$ to $800{ }^{\circ} \mathrm{C}$ at a heating rate of $10^{\circ} \mathrm{C} \mathrm{min}^{-1}$ under a nitrogen flow.
The electrical conductivity was measured using an electrometer (Keithley, model 17A) at room temperature in air. A custom-built two-point probe was used as a fixture for each PEDOT:PSS pellet. The graph between $I$ ( $y$-axis) and $V$ ( $x$-axis) was plotted to obtain the $I-V$ slope, which was used to calculate the electrical conductivity according to eqn (3): $:^{30}$

$$
\sigma=I / K V t=(I-V) \text { slope } / K t
$$

where, $I$ is the current (A), $V$ is the applied voltage (V), $t$ is the sample thickness $(\mathrm{cm})$, and $K$ is the correction factor calculated using a silicon wafer as the reference. PEDOT:PSS pellets with $0.7 \pm 0.3 \mathrm{~mm}$ thickness and $1.3 \mathrm{~cm}$ diameter were prepared by compressing the PEDOT:PSS powder with a hydraulic press machine.

\section{Results and discussion}

The PEDOT:PSS powder was synthesized via chemical oxidative polymerization following the procedure shown in Scheme 1. In the initial step, $\mathrm{Na}_{2} \mathrm{~S}_{2} \mathrm{O}_{8}$ as the oxidant dissociates into sodium ions and a persulfate ion, where the persulfate ion can homolytically dissociate into sulfate radicals in aqueous solution, as shown in Scheme 1(a). ${ }^{31}$ In the oxidation step, an EDOT monomer is oxidized to an EDOT radical cation by the sulfate radical, leading to the formation of sulfate anions, as shown in Scheme $1(\mathrm{~b}){ }^{32}$ For the propagation and doping step, the coupling of EDOT radical cations generates two protons, which are removed in this step. Simultaneously, the PSS and sulfate ions acting as dopants can interact with the oxidized PEDOT chains during the polymerization. The sodium ion from the oxidant can also react with the PSS chains, as illustrated in Scheme 1(c).

\subsection{Structural conformation of PEDOT:PSS}

3.1.1 FTIR analysis. The functional groups of PEDOT:PSS synthesized under various conditions were characterized via FTIR, as shown in Fig. 1. The FTIR spectrum of PEDOT:PSS (Fig. 1(a)), at the EDOT: PSS weight ratio of $1: 11$ and EDOT : $\mathrm{Na}_{2} \mathrm{~S}_{2} \mathrm{O}_{8}$ mole ratio of $1: 2$ shows peaks at 1640 and $1518 \mathrm{~cm}^{-1}$, which are assigned to the $\mathrm{C}=\mathrm{C}$ stretching in the aromatic rings of $\mathrm{PSS}^{33}$ and the $\mathrm{C}=\mathrm{C}$ stretching in the thiophene ring of PEDOT, ${ }^{34}$ respectively. The peak at $1340 \mathrm{~cm}^{-1}$ indicates the $\mathrm{C}-\mathrm{C}$ stretching from the thiophene ring of PEDOT. ${ }^{34}$ The symmetric stretching and antisymmetric stretching of $\mathrm{S}=\mathrm{O}$ can be seen at 1198 and $1055 \mathrm{~cm}^{-1}$, respectively, belonging to PSS and $\mathrm{SO}_{4}{ }^{2-}$ from the oxidant. ${ }^{34}$ The peaks at 1145 and $983 \mathrm{~cm}^{-1}$ can be attributed to the $\mathrm{S}-\mathrm{O}$ stretching in PSS and $\mathrm{SO}_{4}{ }^{2-}$ from the oxidant and the S-phenyl bond in PSS, respectively. ${ }^{35}$ The three peaks at 936, 840, and $691 \mathrm{~cm}^{-1}$ correspond to the C-S stretching of the thiophene ring in PEDOT. ${ }^{35}$ The two peaks at 1144 and $1092 \mathrm{~cm}^{-1}$ are correspond to the $\mathrm{C}-\mathrm{O}$ stretching of PEDOT. ${ }^{23}$ The peaks at 3415 , and $2921 \mathrm{~cm}^{-1}$ correspond to the $\mathrm{O}-\mathrm{H}$ stretching of PSS and $\mathrm{C}-\mathrm{H}$ stretching of PEDOT and PSS, respectively, resulting from PSS incorporated in the PEDOT chain. ${ }^{34}$ For the PEDOT:PSS synthesized without surfactant at various 
(a) Dissociation of $\mathrm{Na}_{2} \mathrm{~S}_{2} \mathrm{O}_{8}$ (Oxidant)

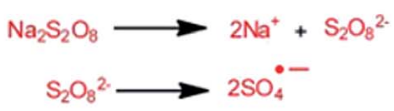

(c) Propagation and doping steps (b) Oxidation step of monomer

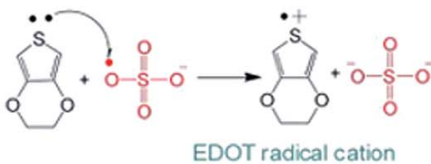

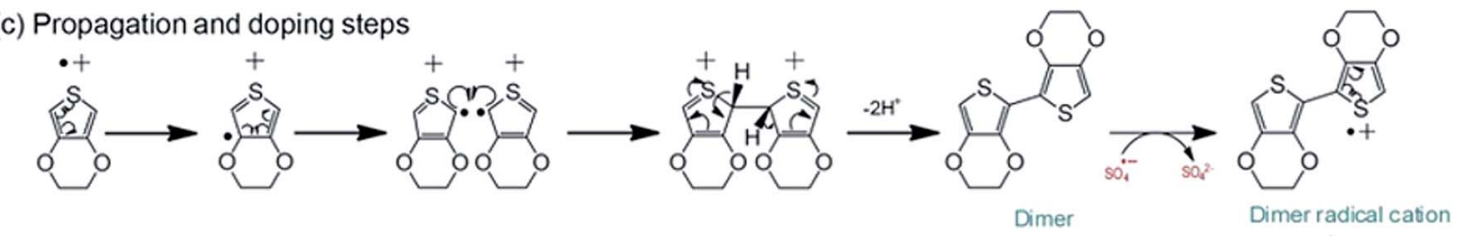

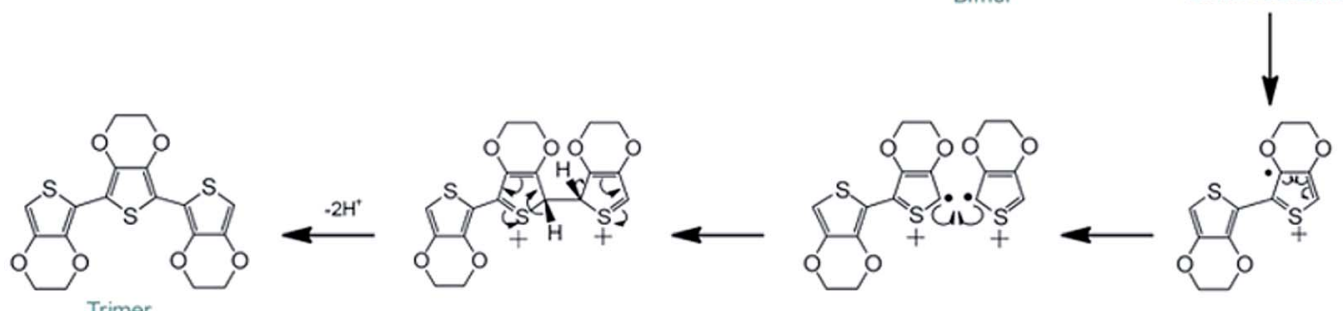<smiles></smiles><smiles>Cc1cc(C(C)C)sc1-c1sc(-c2sc(-c3sc(-c4sc(-c5sc(-c6sc(C(C)C)c7c6OCCO7)c6c5OCCO6)c5c4OCCO5)c4c3OCCO4)c3c2OCCO3)c2c1OCCO2</smiles>

$\mathrm{SO}_{4}{ }^{2+}, \mathrm{Na}^{*}$
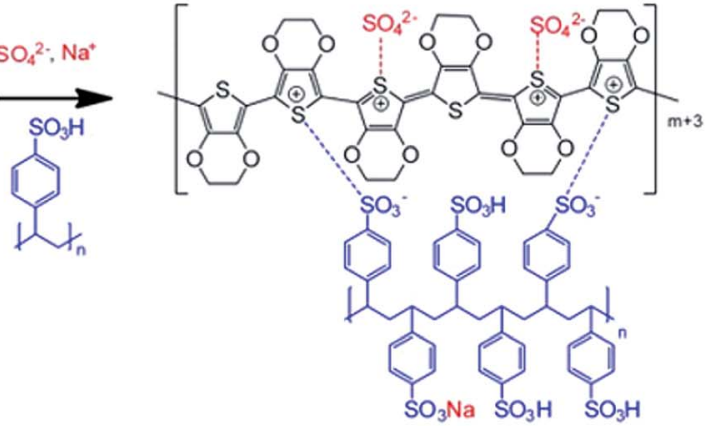

Scheme 1 Proposed mechanism for the oxidative polymerization of PEDOT:PSS.

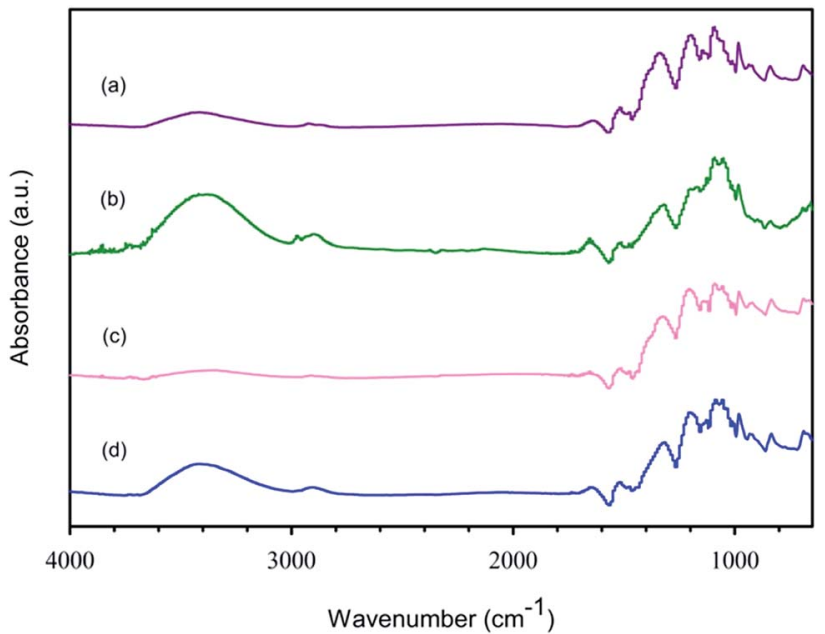

Fig. 1 FTIR spectra of PEDOT:PSS at the EDOT : PSS weight ratio of $1: 11$ and EDOT : $\mathrm{Na}_{2} \mathrm{~S}_{2} \mathrm{O}_{8}$ mole ratio of $1: 2$ with various surfactant types: (a) no surfactant, (b) CTAB (2.5CMC), (c) SDS (2.5CMC), and (d) Triton X-100 (2.5CMC).
EDOT : PSS weight ratios and EDOT : $\mathrm{Na}_{2} \mathrm{~S}_{2} \mathrm{O}_{8}$ mole ratios, their FTIR spectra showed the same functional groups as that with the EDOT : PSS weight ratio of $1: 11$ and EDOT : $\mathrm{Na}_{2} \mathrm{~S}_{2} \mathrm{O}_{8}$ mole ratio of $1: 2$. The FTIR spectra of the synthesized PEDOT:PSS (Fig. 1(a)) are similar to the PEDOT:PSS spectrum reported by Chanthanont and Sirivat, 2013. ${ }^{23}$

The FTIR spectrum of PEDOT:PSS synthesized in CTAB (Fig. 1(b)) shows peaks at 2973 and $2898 \mathrm{~cm}^{-1}$, indicating the $\mathrm{CH}_{3}-\mathrm{N}^{+}$anti-symmetric stretching and $\mathrm{C}-\mathrm{H}$ stretching, respectively, which confirm the incorporation of CTAB in PEDOT:PSS. ${ }^{36}$ In the case of PEDOT:PSS prepared with SDS (Fig. 1(c)), the O-H stretching peak shifts from 3415 to $3339 \mathrm{~cm}^{-1}$ because SDS can repel the O-H of PSS by electrorepulsive forces. ${ }^{37}$ For the system of Triton X-100, the FTIR spectrum of PEDOT:PSS (Fig. 1(d)) is the same as that without surfactant, and it does not show any characteristic peaks of Triton X-100. Thus, Triton X-100 was not incorporated in PEDOT:PSS.

For the PEDOT:PSS synthesized at various CTAB concentrations, at the EDOT:PSS weight ratio of $1: 11$ and 
EDOT : $\mathrm{Na}_{2} \mathrm{~S}_{2} \mathrm{O}_{8}$ mole ratio of $1: 2$, the spectra show the $\mathrm{CH}_{3}-$ $\mathrm{N}^{+}$anti-symmetric stretching of CTAB at $2973 \mathrm{~cm}^{-1}$ and the $\mathrm{C}-\mathrm{H}$ stretching peak at $2898 \mathrm{~cm}^{-1},{ }^{36}$ where the intensity of the former increased with an increase in CTAB concentration. In the case of various SDS concentrations, the intensity of the $\mathrm{O}-\mathrm{H}$ stretching peak of SDS located at $3339 \mathrm{~cm}^{-1}$ (ref. 38) increased with an increase in SDS concentration. Under various Triton X100 concentrations, the FT-IR spectra of PEDOT:PSS were nearly the same with an increase in Triton X-100 concentration.

3.1.2 FT Raman analysis. The PEDOT:PSS synthesized at the EDOT : PSS weight ratios of $1: 5,1: 11$, and $1: 13$ and EDOT : $\mathrm{Na}_{2} \mathrm{~S}_{2} \mathrm{O}_{8}$ mole ratio fixed at $1: 1$ were characterized using the FT Raman technique. The FT Raman spectra showed the dominant peak at $1424 \mathrm{~cm}^{-1}$, indicative of the $\mathrm{C}_{\alpha}-\mathrm{C}_{\beta}$ stretching vibration mode of the quinoid structure in PEDOT. ${ }^{39}$ The quinoid structure represents the linear structure or the expanded-coil of the PEDOT:PSS chain, which lies on the same plane. Hence, the conjugated $\pi$-electrons can delocalize in the PEDOT chain..$^{40}$ The PEDOT:PSS synthesized at the EDOT : PSS weight ratio of $1: 11$ and EDOT: $\mathrm{Na}_{2} \mathrm{~S}_{2} \mathrm{O}_{8}$ mole ratio of $1: 2$ with Triton-X 100 (2.5CMC) was also characterized via FT-Raman spectroscopy and it was observed that the FT-Raman spectrum with the surfactant was similar to that without surfactant, indicating the same quinoid structure in the PEDOT chain.

\subsection{X-ray diffraction}

The XRD patterns of PEDOT:PSS with different EDOT : PSS weight ratios at the EDOT : $\mathrm{Na}_{2} \mathrm{~S}_{2} \mathrm{O}_{8}$ mole ratio of $1: 1$ are shown in Fig. 2. The two main peaks at $2 \theta=17.7^{\circ}$ and $25.8^{\circ}$ refer to the amorphous halo diffraction of PSS and the interchain packing of PEDOT, respectively. ${ }^{41}$ At the EDOT : PSS weight ratios ranging from $1: 9$ to $1: 11$, the peaks in the XRD patterns show a shift from $25.5^{\circ}$ to $25.8^{\circ}$, which is consistent with the smaller $d$-spacings between the PEDOT chains ranging from $3.48 \AA$ to $3.45 \AA$. However, the intensities of the crystalline peaks of EDOT : PSS at the weight ratio of $1: 11$ were lower than that of the other EDOT : PSS weight ratios, suggesting that the PEDOT:PSS at this condition possessed a lower PSSNa content. PSSNa is a salt that reduces the available doping sites on PSS, and hence induces charge screening between PEDOT and PSS. ${ }^{42}$ Zotti et al., 2003, reported that the electrical conductivity of PEDOT:PSS was reduced due the presence of PSSNa in PEDOT:PSS. ${ }^{43}$

Fig. 3 illustrates the XRD patterns of commercial PSSNa and PEDOT:PSS synthesized using various EDOT : $\mathrm{Na}_{2} \mathrm{~S}_{2} \mathrm{O}_{8}$ mole ratios at the EDOT : PSS weight ratio of $1: 11$. The PSSNa XRD pattern showed crystalline peaks at $19.1^{\circ}, 23.2^{\circ}, 28.1^{\circ}, 29.1^{\circ}$, $32.2^{\circ}, 34.0^{\circ}, 38.7^{\circ}$ and $48.9^{\circ} .{ }^{44}$ The two main peaks of PEDOT:PSS are evident at $2 \theta=17.7^{\circ}$ and $2 \theta=25.8^{\circ}$, similar to the results in Fig. 2. However, the intensities of the crystalline peak of PSSNa incorporated in PEDOT:PSS tended to increase with an increase in EDOT : $\mathrm{Na}_{2} \mathrm{~S}_{2} \mathrm{O}_{8}$ mole ratio because sodium ions from the oxidant are more prone to interact with PSS molecules by electrostatic interaction. ${ }^{44}$ The increase in PSSNa with an increase in EDOT: $\mathrm{Na}_{2} \mathrm{~S}_{2} \mathrm{O}_{8}$ mole ratio was further investigated by XPS.

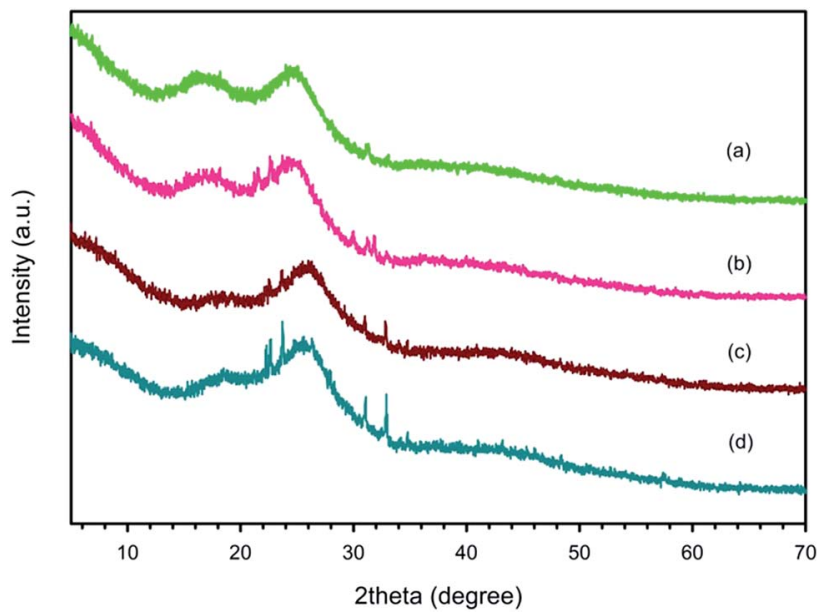

Fig. 2 XRD spectra of PEDOT:PSS at the EDOT: $\mathrm{Na}_{2} \mathrm{~S}_{2} \mathrm{O}_{8}$ mole ratio of $1: 1$ and at various EDOT : PSS weight ratios: (a) EDOT : PSS weight ratio of $1: 1$, (b) EDOT : PSS weight ratio of $1: 5$, (c) EDOT : PSS weight ratio of $1: 11$, and (d) EDOT : PSS weight ratio of $1: 13$.

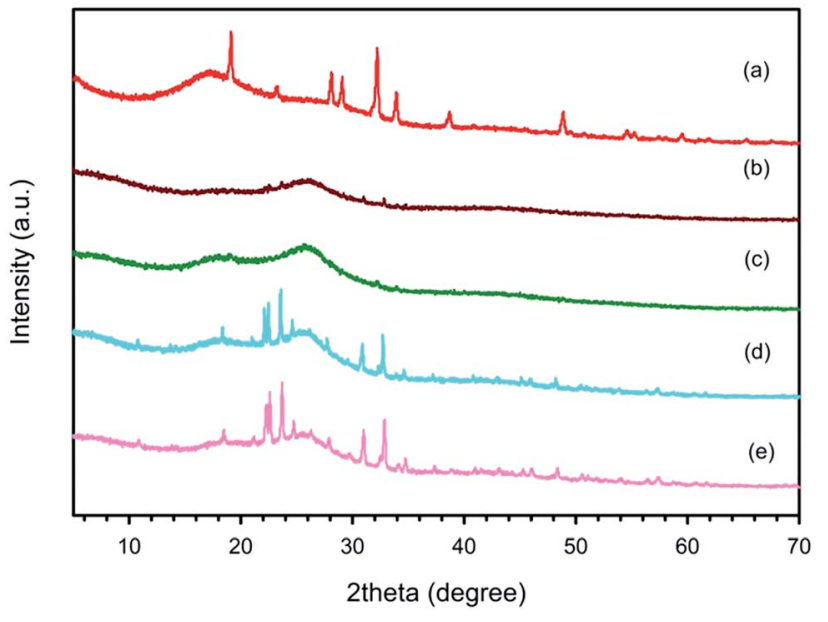

Fig. 3 XRD spectra of commercial PSSNa and PEDOT:PSS at the EDOT : PSS weight ratio of 1 : 11 and at various EDOT : $\mathrm{Na}_{2} \mathrm{~S}_{2} \mathrm{O}_{8}$ mole ratios: (a) PSSNa, and EDOT : $\mathrm{Na}_{2} \mathrm{~S}_{2} \mathrm{O}_{8}$ mole ratio of (b) $1: 1$, (c) $1: 2$, (d) $1: 3$ and (e) $1: 4$.

The PEDOT:PSS synthesized using various surfactant types and concentrations at the EDOT : PSS weight ratio of $1: 11$ and EDOT : $\mathrm{Na}_{2} \mathrm{~S}_{2} \mathrm{O}_{8}$ mole ratio of $1: 2$ were also investigated via XRD. The obtained XRD patterns were nearly the same as that without surfactant, suggesting the surfactants did not affect the crystallinity of PEDOT:PSS.

\subsection{X-ray photoelectron spectroscopy}

The element analysis and chemical bonding of the synthesized PEDOT:PSS were characterized by XPS. The wide-scan XPS spectra of PEDOT:PSS revealed the peaks of Na 1s, O 1s, C 1s, and $S$ 2p located at 1066.0, 527.0, 280.0, and $163.0 \mathrm{eV}$, respectively. The existence of $\mathrm{Na}$ in $\mathrm{PSSNa}^{44}$ is due to the interaction of $\mathrm{PSS}^{-}$and $\mathrm{Na}^{+}$from the oxidant. The high-resolution scan XPS 
Table 1 XPS deconvoluted contribution of S (sulphur) 2p of PEDOT:PSS synthesized at various conditions

Sample code

$\%$ PEDOT \% $\mathrm{PSS}^{-}$and $\% \mathrm{SO}_{4}{ }^{2-} \% \mathrm{PSSNa}$

Effect of PSS (no surfactant)

Pure PEDOT (without PSS)

EDOT : PSS weight ratio of $1: 1$ and EDOT : $\mathrm{Na}_{2} \mathrm{~S}_{2} \mathrm{O}_{8}$ mole ratio of $1: 1$

EDOT : PSS weight ratio of $1: 11$ and EDOT $: \mathrm{Na}_{2} \mathrm{~S}_{2} \mathrm{O}_{8}$ mole ratio of $1: 1$

EDOT : PSS weight ratio of $1: 13$ and EDOT $: \mathrm{Na}_{2} \mathrm{~S}_{2} \mathrm{O}_{8}$ mole ratio of $1: 1$

$\begin{array}{lll}85.41 & 14.59 & - \\ 62.96 & 21.23 & 15.89 \\ 31.47 & 45.57 & 22.96 \\ 36.43 & 39.89 & 23.68\end{array}$

Effect of oxidant (no surfactant)

EDOT : PSS weight ratio of $1: 11$ and EDOT $: \mathrm{Na}_{2} \mathrm{~S}_{2} \mathrm{O}_{8}$ mole ratio of $1: 1$ EDOT : PSS weight ratio of $1: 11$ and EDOT : $\mathrm{Na}_{2} \mathrm{~S}_{2} \mathrm{O}_{8}$ mole ratio of $1: 2$ EDOT : PSS weight ratio of $1: 11$ and EDOT : $\mathrm{Na}_{2} \mathrm{~S}_{2} \mathrm{O}_{8}$ mole ratio of $1: 4$

$\begin{array}{lll}31.47 & 45.57 & 22.96 \\ 29.05 & 50.59 & 20.36 \\ 19.56 & 35.27 & 45.13 \\ & & \\ & & \\ 27.80 & 49.78 & 22.42 \\ 45.40 & 37.52 & 17.08 \\ 42.53 & 37.42 & 20.05 \\ 47.81 & 36.46 & 19.22 \\ 15.34 & 30.57 & 54.09 \\ 45.82 & 34.32 & 19.87\end{array}$

Effect of surfactant

EDOT : PSS weight ratio of $1: 11$ and EDOT : $\mathrm{Na}_{2} \mathrm{~S}_{2} \mathrm{O}_{8}$ mole ratio of $1: 2$ with Triton X-100 (at CMC) 27.80 EDOT : PSS weight ratio of $1: 11$ and EDOT : $\mathrm{Na}_{2} \mathrm{~S}_{2} \mathrm{O}_{8}$ mole ratio of $1: 2$ with Triton X-100 (at 2.5CMC) 45.40 EDOT : PSS weight ratio of $1: 11$ and EDOT $: \mathrm{Na}_{2} \mathrm{~S}_{2} \mathrm{O}_{8}$ mole ratio of $1: 2$ with Triton X-100 (at 5CMC) 42.53 EDOT : PSS weight ratio of $1: 11$ and EDOT $: \mathrm{Na}_{2} \mathrm{~S}_{2} \mathrm{O}_{8}$ mole ratio of $1: 2$ with Triton X-100 (at 10CMC) 47.81 EDOT : PSS weight ratio of $1: 11$ and EDOT : $\mathrm{Na}_{2} \mathrm{~S}_{2} \mathrm{O}_{8}$ mole ratio of $1: 2$ with CTAB (at 2.5CMC) 15.34 EDOT : PSS weight ratio of $1: 11$ and EDOT $: \mathrm{Na}_{2} \mathrm{~S}_{2} \mathrm{O}_{8}$ mole ratio of $1: 2$ with SDS (at 2.5CMC) 45.82

34.32

19.87

spectra of S 2p showed the deconvolution of S 2p of PEDOT:PSS, which indicated the $\mathrm{C}-\mathrm{S}$ of PEDOT was located at 163.22 and $164.46 \mathrm{eV},{ }^{45} \mathrm{~S}=\mathrm{O}$ of $\mathrm{SO}_{4}{ }^{2-}$ from the oxidant and $\mathrm{S}=\mathrm{O}$ of $\mathrm{SO}_{3}{ }^{-}$ from PSS at 168.21 and $169.10 \mathrm{eV},{ }^{46,47}$ respectively, and $\mathrm{S}=\mathrm{O}$ from PSSNa at 169.81 and $170.59 \mathrm{eV}^{\mathbf{4 8 , 4 9}}$ The element and chemical bonding of PEDOT (without PSS) was also investigated via XPS for comparison with PEDOT:PSS. The wide-scan XPS spectrum of pure PEDOT showed the elements $\mathrm{C} 1 \mathrm{~s}, \mathrm{O} 1 \mathrm{~s}$, and $\mathrm{S}$ $2 \mathrm{p}$ without Na. Thus, it can be confirmed that PSS is the main component inducing the formation of PSSNa. The deconvolution of S 2p indicated the $\mathrm{C}-\mathrm{S}$ of the pure PEDOT at 163.22 and $164.46 \mathrm{eV},{ }^{50}$ and $\mathrm{S}=\mathrm{O}$ of $\mathrm{SO}_{4}{ }^{2-}$ from the oxidant at 167.53 and $168.59 \mathrm{eV},{ }^{47}$ suggesting that $\mathrm{SO}_{4}{ }^{2-}$ from the oxidant acts as a dopant by interacting with PEDOT through electrostatic interaction. ${ }^{\mathbf{1 2}}$ The $\mathrm{S}=\mathrm{O}$ of PSSNa was not found in the $\mathrm{S} 2 \mathrm{p}$ deconvolution of the pure PEDOT (without PSS), while it was present for PEDOT:PSS. The atom percentages of the sulphur species from PEDOT, $\mathrm{PSS}^{-}, \mathrm{SO}_{4}{ }^{2-}$ and PSSNa are tabulated in Table 1, where both $\mathrm{PSS}^{-}$and $\mathrm{SO}_{4}{ }^{2-}$ act as dopants for the oxidized PEDOT chain.

For the effect of EDOT:PSS weight ratios, at the EDOT : $\mathrm{Na}_{2} \mathrm{~S}_{2} \mathrm{O}_{8}$ mole ratio of $1: 1$, Table 1 shows that the $\%$ $\mathrm{PSS}^{-}$and $\% \mathrm{SO}_{4}{ }^{2-}$ tended to increase with an increase in EDOT : PSS weight ratio because PSS $^{-}$acts as a dopant. However, at the EDOT : PSS weight ratio of $1: 13$, the decrease in $\% \mathrm{PSS}^{-}$and $\% \mathrm{SO}_{4}{ }^{2-}$ was due to the over-doping or excessive PSS. ${ }^{51}$ In the present work, the PEDOT:PSS synthesized at the EDOT : PSS weight ratio of $1: 11$ possessed the highest \% $\mathrm{PSS}^{-}$ and $\% \mathrm{SO}_{4}{ }^{2-}$ compared to other EDOT : PSS weight ratios and with a low \% PSSNa. Thus, the high amount of dopants (\% $\mathrm{PSS}^{-}$ and $\% \mathrm{SO}_{4}{ }^{2-}$ ) is available to provide a high number of charge carriers. $^{52}$ On the other hand, PSSNa reduces the number of doping sites on PSS, and thus induces charge screening between the PEDOT and PSS chains. ${ }^{42}$ Therefore, EDOT : PSS at the weight ratio of $1: 11$ is optimal for the synthesis of PEDOT:PSS.
For the effect of EDOT: $\mathrm{Na}_{2} \mathrm{~S}_{2} \mathrm{O}_{8}$ mole ratio, at the EDOT : PSS weight ratio of $1: 11$, the EDOT : $\mathrm{Na}_{2} \mathrm{~S}_{2} \mathrm{O}_{8}$ mole ratio of $1: 2$ possessed the highest $\% \mathrm{PSS}^{-}$and $\% \mathrm{SO}_{4}{ }^{2-}$ $(50.59 \%)$, while the \% PSSNa was relatively low $(20.36 \%)$, as shown in Table 1 . The increase in $\% \mathrm{PSS}^{-}$and $\% \mathrm{SO}_{4}{ }^{2-}$ is because the $\mathrm{SO}_{4}{ }^{2-}$ ions from the oxidant prefer to interact with the PEDOT chain. However, at a higher EDOT : $\mathrm{Na}_{2} \mathrm{~S}_{2} \mathrm{O}_{8}$ mole ratio, the PSSNa content tends to increase as $\mathrm{Na}^{+}$ions from the oxidant largely interact with $\mathrm{PSS}^{-}$to form PSSNa. ${ }^{44}$ This suggests that the PEDOT:PSS interaction is reduced by the existence of PSSNa via a reduction in doping sites and its screening. Thus, the EDOT : $\mathrm{Na}_{2} \mathrm{~S}_{2} \mathrm{O}_{8}$ mole ratio of $1: 2$ is optimal since it provided the highest dopant content (\% $\mathrm{PSS}^{-}$ and $\% \mathrm{SO}_{4}{ }^{2-}$ ), while \% PSSNa is relatively low.

For the effect of surfactant type, at the EDOT : PSS weight ratio of $1: 11$ and the EDOT : $\mathrm{Na}_{2} \mathrm{~S}_{2} \mathrm{O}_{8}$ mole ratio of $1: 2$, each surfactant differently affected the presence of sulphur species in PEDOT:PSS. The PEDOT:PSS synthesized with CTAB (2.5CMC) possessed a lower $\% \mathrm{PSS}^{-}$and $\% \mathrm{SO}_{4}{ }^{2-}$ than that with SDS and Triton X-100, respectively, as shown in Table 1. CTAB is a cationic surfactant, which can interact with $\mathrm{PSS}^{-}$(negatively charged) via electrostatic interaction, and thus reduces the interaction between PEDOT and PSS. ${ }^{53}$ For the SDS system (2.5CMC), SDS is an anionic surfactant, which prefers to interact with PEDOT instead of PSS $^{-},{ }^{37}$ resulting in a higher \% PEDOT than that without surfactant. For the Triton X-100 system (2.5CMC), the PEDOT:PSS possessed a higher \% $\mathrm{PSS}^{-}$ and $\% \mathrm{SO}_{4}{ }^{2-}$ and a lower \% PSSNa than that with the other two surfactants.

For effect of Triton X-100 concentration, as shown in Table 1, Triton X-100 forms micelles at its $\mathrm{CMC},{ }^{30}$ but they are unstable. At high Triton X-100 concentrations of 2.5CMC, 5CMC and 10CMC, the \% PSSNa was lower, while \% $\mathrm{PSS}^{-}$and $\% \mathrm{SO}_{4}{ }^{2-}$ decreased with an increase in concentration. Triton X-100 is a non-ionic surfactant that can interact with both PEDOT and PSS. However, the resulting TX-PSS complex can be easily 


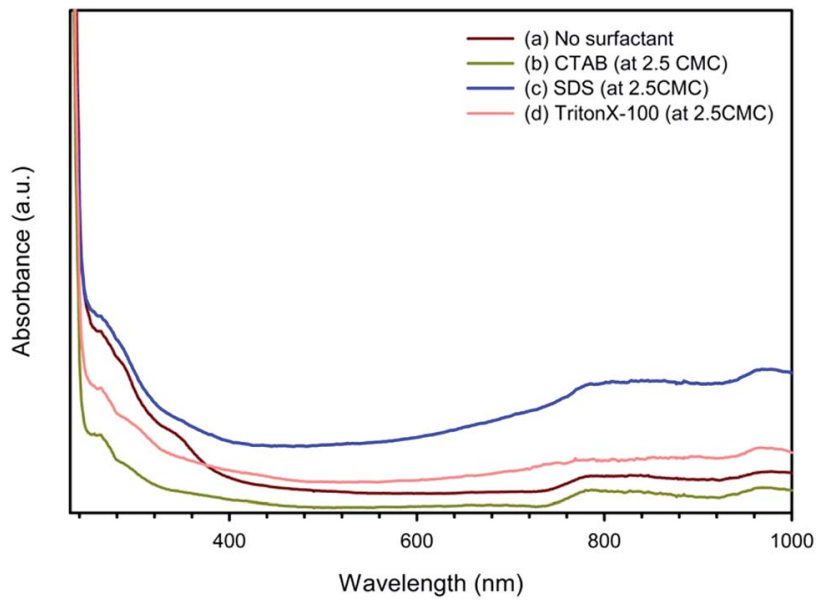

Fig. 4 UV adsorption spectra of PEDOT:PSS at the EDOT : PSS weight ratio of $1: 11$ and EDOT : $\mathrm{Na}_{2} \mathrm{~S}_{2} \mathrm{O}_{8}$ mole ratio of $1: 2$ using various surfactant types: (a) no surfactant, (b) CTAB (at 2.5CMC), (c) SDS (at $2.5 \mathrm{CMC}$ ), and (d) Triton $\mathrm{X}-100$ (at 2.5CMC).

removed by washing with methanol, ${ }^{54}$ resulting in the simultaneous removal of PSS ${ }^{-}$as a dopant and PSSNa as a salt. This suggests that Triton X-100 at higher concentrations than 2.5CMC reduces the PEDOT and PSS interaction as well as the PSSNa amount.

\subsection{UV-visible spectroscopy}

3.4.1 Characteristics of UV spectra. The UV adsorption spectra of PEDOT:PSS synthesized at the EDOT : PSS weight ratio of $1: 11$ and EDOT $: \mathrm{Na}_{2} \mathrm{~S}_{2} \mathrm{O}_{8}$ mole ratio of $1: 2$ with surfactants (at 2.5CMC) and without surfactant are shown in Fig. 4. All the UV spectra show a UV absorbance at $258 \mathrm{~nm}$, which can be assigned to the substituted phenyl groups in PSS. ${ }^{55}$ The broad bands between 600 and $900 \mathrm{~nm}$ and between 700 to $1000 \mathrm{~nm}$ can be ascribed to the polaron and bipolaron states of PEDOT:PSS, respectively, indicative of the characteristic doped state of PEDOT:PSS. ${ }^{25}$
For the effects of EDOT : PSS weight ratio and EDOT : $\mathrm{Na}_{2}-$ $\mathrm{S}_{2} \mathrm{O}_{8}$ mole ratio, the characteristics of the PEDOT:PSS UVspectra were nearly the same with an increase in EDOT : PSS weight ratio or increase in EDOT : $\mathrm{Na}_{2} \mathrm{~S}_{2} \mathrm{O}_{8}$ mole ratio, consistent with previous work of Khan and Narula, 2016. ${ }^{25}$

3.4.2 Band gap energy. The band gap energy of PEDOT:PSS was calculated by using the Tauc relation (eqn (1)), as tabulated in Table 2. In the case of various EDOT : PSS weight ratios, the band gap energy of PEDOT:PSS prepared at the EDOT : PSS weight ratio of $1: 5(2.92 \mathrm{eV})$ WAS higher than that for the EDOT : PSS weight ratio of $1: 11(2.67 \mathrm{eV})$. This indicates that at a higher PSS content, a larger number of $\mathrm{SO}_{3}{ }^{-}$groups from PSS is available to interact with PEDOT. $^{13}$ However, at the EDOT : PSS weight ratio of $1: 13$, the band gap energy is higher at $2.72 \mathrm{eV}$ due to the over-doping. ${ }^{51}$

For the effect of EDOT: $\mathrm{Na}_{2} \mathrm{~S}_{2} \mathrm{O}_{8}$ mole ratio, at the EDOT : PSS weight ratio of $1: 11$, the band gap energy of the EDOT : $\mathrm{Na}_{2} \mathrm{~S}_{2} \mathrm{O}_{8}$ mole ratio of $1: 2$ possessed the lowest value of $1.90 \mathrm{eV}$. This is due to the $\mathrm{SO}_{4}{ }^{2-}$ ions from the oxidant interacting with the PEDOT chains as a dopant. This result is consistent with the increments in $\% \mathrm{PSS}^{-}$and $\% \mathrm{SO}_{4}{ }^{2-}$ determined by XPS. The doping process generally reduces the band gap energy between the HOMO and the LUMO to a level between 1-4 eV, as reported by Kar et al., 2013. ${ }^{2}$ However, the band gap energy for the EDOT : $\mathrm{Na}_{2} \mathrm{~S}_{2} \mathrm{O}_{8}$ mole ratio of $1: 4$ is larger because a large number of $\mathrm{Na}^{+}$ions from the oxidant can interact with the PSS $^{-}$chains to form $\mathrm{PSSNa}^{\mathbf{4 4}}$ which reduces the amount of doping sites on PSS. This result is consistent with the XPS result, indicating an increase in PSSNa, and the XRD result showing the highly crystalline peaks of PSSNa.

For the effect of surfactant type on the band gap energy of PEDOT:PSS, at the EDOT : PSS weight ratio of $1: 11$ and EDOT : $\mathrm{Na}_{2} \mathrm{~S}_{2} \mathrm{O}_{8}$ mole ratio of $1: 2$ utilizing Triton X-100 at 2.5CMC, this condition provided a band gap energy of $1.80 \mathrm{eV}$, which is lower than that of $3.00 \mathrm{eV}$ for $2.5 \mathrm{CMC}$ SDS and $3.5 \mathrm{eV}$ for 2.5CMC CTAB. Triton X-100 at 2.5CMC increases the HOMO level, allowing the polarons and bipolarons to delocalize. ${ }^{2}$ CTAB and SDS provide higher band gap energies since they can

Table 2 Band gap and UV adsorption information

Sample code

$E_{\mathrm{g}}(\mathrm{eV})$

Effect of PSS (no surfactant)

EDOT : PSS weight ratio of $1: 5$ and EDOT : $\mathrm{Na}_{2} \mathrm{~S}_{2} \mathrm{O}_{8}$ mole ratio of $1: 1$

EDOT : PSS weight ratio of $1: 11$ and EDOT : $\mathrm{Na}_{2} \mathrm{~S}_{2} \mathrm{O}_{8}$ mole ratio of $1: 1$

EDOT : PSS weight ratio of $1: 13$ and EDOT $: \mathrm{Na}_{2} \mathrm{~S}_{2} \mathrm{O}_{8}$ mole ratio of $1: 1$

Effect of oxidant (no surfactant)

EDOT : PSS weight ratio of $1: 11$ and EDOT : $\mathrm{Na}_{2} \mathrm{~S}_{2} \mathrm{O}_{8}$ mole ratio of $1: 1$

Effect of surfactant

EDOT : PSS weight ratio of $1: 11$ and EDOT : $\mathrm{Na}_{2} \mathrm{~S}_{2} \mathrm{O}_{8}$ mole ratio of $1: 2$ with Triton X-100 (at CMC) 

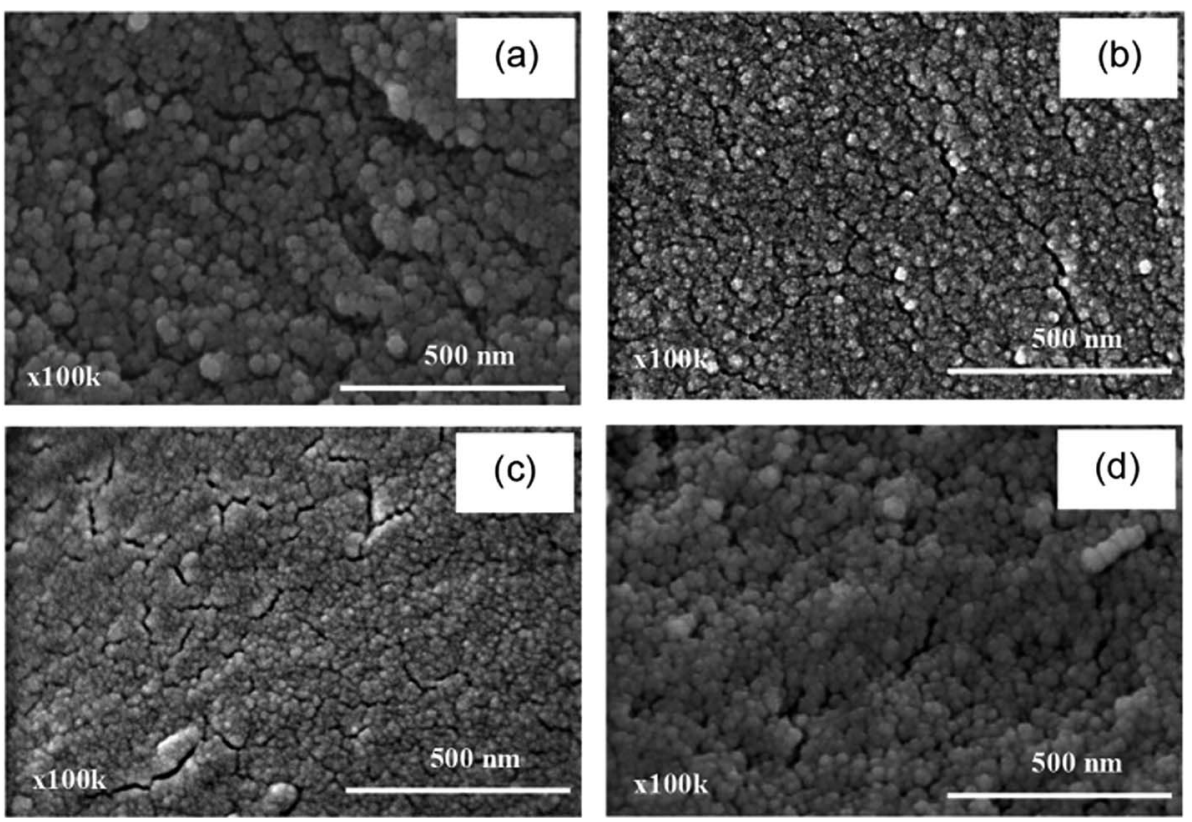

Fig. 5 PEDOT:PSS surface morphology at the EDOT : $\mathrm{Na}_{2} \mathrm{~S}_{2} \mathrm{O}_{8}$ mole ratio of $1: 1$ and at various EDOT : PSS weight ratios: EDOT : PSS weight ratio of (a) $1: 1$, (b) $1: 5$, (c) $1: 11$ and (d) $1: 13$

obstruct the interaction of PSS with PEDOT, resulting in higher energy barriers between the HOMO and LUMO levels.

For the effect of Triton X-100 concentrations, a higher concentration provides a higher band gap energy above 2.5 CMC, as shown in Table 2, where too many Triton X-100 molecules can obstruct the PEDOT and PSS interaction and form the TX-PSS complex, but can be removed by methanol washing..$^{54}$ The optimum Triton-X 100 concentration is $2.5 \mathrm{CMC}$ due to its lowest band gap energy $(1.80 \mathrm{eV})$.

\subsection{Morphology of PEDOT:PSS}

The PEDOT:PSS morphology was investigated via FE-SEM. The effect of EDOT : PSS weight ratios at the EDOT : $\mathrm{Na}_{2} \mathrm{~S}_{2} \mathrm{O}_{8}$ mole ratio of $1: 1$ on the PEDOT:PSS morphology is shown Fig. 5 . The particle shapes are all spherical, as tabulated in Table 3 . The PEDOT:PSS particle shapes were all spherical because PSS forms spherical micelles. ${ }^{56}$ It can be noted that the packing parameter, $V_{\mathrm{H}} / l_{\mathrm{c}} a_{0}$, is less than $1 / 3$ (where, $V_{\mathrm{H}}$ is the volume occupied by the hydrophobic groups in the micelle core, $l_{\mathrm{c}}$ is the length of the hydrophobic group in the core, and $a_{0}$ is the crosssectional area occupied by the hydrophilic groups), indicating a spherical micelle. ${ }^{57}$ The particle sizes of PEDOT:PSS at the EDOT : PSS weight ratios of $1: 1,1: 5,1: 11$, and $1: 13$ are $33.20 \pm 4.29,16.57 \pm 1.99,16.26 \pm 1.40$, and $17.19 \pm 2.05 \mathrm{~nm}$, respectively, as tabulated in Table 3 . The particle size of PEDOT:PSS decreased with an increase in PSS because PSS is an anionic surfactant, ${ }^{58}$ which forms PSS micelles at the CMC of 7 $\times 10^{-5} \mathrm{~mol} \mathrm{~L}^{-1}$. The EDOT : PSS weight ratio of $1: 5$ is the condition of 4.75CMC PSS, and thus the average particle size of PEDOT:PSS became smaller. Above the EDOT : PSS weight ratio of $1: 5$, the particle size of PEDOT:PSS is not significantly different.
For the effect of EDOT: $\mathrm{Na}_{2} \mathrm{~S}_{2} \mathrm{O}_{8}$ mole ratio at the EDOT : PSS weight ratio of $1: 11$, the particle shapes and sizes are tabulated Table 3. The particle sizes of PEDOT:PSS at the weight ratio of $1: 11$ and EDOT : $\mathrm{Na}_{2} \mathrm{~S}_{2} \mathrm{O}_{8}$ mole ratios of $1: 1$, $1: 1.5,1: 2,1: 2.5,1: 3$, and $1: 4$ are $16.26 \pm 1.40,17.28 \pm$ $2.07,19.84 \pm 2.36,21.82 \pm 2.36,22.95 \pm 2.20$, and $23.97 \pm$ $3.48 \mathrm{~nm}$, respectively. The particle size of PEDOT:PSS increased monotonically with an increase in EDOT : $\mathrm{Na}_{2} \mathrm{~S}_{2} \mathrm{O}_{8}$ mole ratio. This result is possibly derived from many successive steps: a larger oxidant amount yields a faster nucleation rate for EDOT radical ions; PEDOT chains are polymerized with a lower molecular weight; easier access into PSS micelles leads to a larger EDOT content in a given PSS micelle volume; and PEDOT chains aggregate to form a larger particle size. Additionally, the oxidant ions $\left(\mathrm{Na}^{+}\right.$and $\left.\mathrm{SO}_{4}{ }^{2-}\right)$ can reduce the electro-repulsion among the $\mathrm{SO}_{3}{ }^{-}$groups of the PSS micelle, leading to an increase in the PSS micelle size, consistent with the effect of salt ions on SDS micelles, as reported by Kim et al., $2001 .^{59}$ The result can be clearly observed in the FE-SEM images of PEDOT:PSS at the EDOT : $\mathrm{Na}_{2} \mathrm{~S}_{2} \mathrm{O}_{8}$ mole ratios of $1: 1$ and $1: 2$, as shown in Fig. 5(c) and 6(a), respectively.

The effect of surfactant type on the PEDOT:PSS morphology at the EDOT : PSS weight ratio of $1: 11$ and the EDOT : $\mathrm{Na}_{2} \mathrm{~S}_{2} \mathrm{O}_{8}$ mole ratio of $1: 2$ using CTAB (cationic surfactant), SDS (anionic surfactant), and Triton X-100 (non-ionic surfactant) at 2.5CMC is shown in Fig. 6(b)-(d), respectively. The particle shapes and sizes of the synthesized PEDOT:PSS are tabulated in Table 3. The shapes of PEDOT:PSS in the three surfactant systems are spherical. The particle size of PEDOT:PSS without surfactant is smaller than that with the surfactants since the PSS micelles are likely disturbed by the surfactant molecules. Among the surfactants, PEDOT:PSS synthesized with CTAB at 
Table 3 The electrical conductivity, shape, and size of PEDOT:PSS synthesized under various conditions

\begin{tabular}{|c|c|c|c|}
\hline Sample code EDOT $:$ PSS and EDOT $: \mathrm{Na}_{2} \mathrm{~S}_{2} \mathrm{O}_{8}$ & $\begin{array}{l}\text { Electrical conductivity } \\
\left(\mathrm{S} \mathrm{cm}^{-1}\right)\end{array}$ & Particle shape & Particle size \\
\hline \multicolumn{4}{|l|}{ Effect of PSS (no surfactant) } \\
\hline wt ratio $1: 1$ and mole ratio $1: 1$ & $452.81 \pm 31.59$ & Spherical & $33.20 \pm 4.29$ \\
\hline wt ratio $1: 3$ and mole ratio $1: 1$ & $366.55 \pm 28.82$ & Spherical & $32.88 \pm 2.88$ \\
\hline wt ratio $1: 5$ and mole ratio $1: 1$ & $250.23 \pm 85.13$ & Spherical & $16.57 \pm 1.99$ \\
\hline wt ratio $1: 7$ and mole ratio $1: 1$ & $477.17 \pm 36.97$ & Spherical & $16.60 \pm 1.77$ \\
\hline wt ratio $1: 9$ and mole ratio $1: 1$ & $828.01 \pm 81.77$ & Spherical & $16.75 \pm 2.81$ \\
\hline wt ratio $1: 11$ and mole ratio $1: 1$ & $999.74 \pm 10.86$ & Spherical & $16.26 \pm 1.40$ \\
\hline wt ratio $1: 13$ and mole ratio $1: 1$ & $524.23 \pm 42.29$ & Spherical & $17.19 \pm 2.05$ \\
\hline \multicolumn{4}{|l|}{ Effect of oxidant (no surfactant) } \\
\hline wt ratio $1: 11$ and mole ratio $1: 1$ & $999.74 \pm 10.86$ & Spherical & $16.26 \pm 1.40$ \\
\hline wt ratio $1: 11$ and mole ratio $1: 1.5$ & $1048.78 \pm 35.10$ & Spherical & $17.28 \pm 2.07$ \\
\hline wt ratio $1: 11$ and mole ratio $1: 2$ & $1556.85 \pm 46.84$ & Spherical & $19.84 \pm 2.36$ \\
\hline wt ratio $1: 11$ and mole ratio $1: 2.5$ & $564.71 \pm 53.44$ & Spherical & $21.82 \pm 2.36$ \\
\hline wt ratio $1: 11$ and mole ratio $1: 3$ & $199.46 \pm 37.51$ & Spherical & $22.95 \pm 2.20$ \\
\hline wt ratio $1: 11$ and mole ratio $1: 4$ & $55.61 \pm 0.10$ & Spherical & $23.97 \pm 3.48$ \\
\hline \multicolumn{4}{|l|}{ Effect of surfactant } \\
\hline wt ratio $1: 11$ and mole ratio $1: 2$ with CTAB (at CMC) & $12.43 \pm 1.33$ & Spherical & $24.98 \pm 2.54$ \\
\hline wt ratio $1: 11$ and mole ratio $1: 2$ with CTAB (at 2.5CMC) & $0.41 \pm 0.06$ & Spherical & $24.46 \pm 2.35$ \\
\hline wt ratio $1: 11$ and mole ratio $1: 2$ with CTAB (at 10CMC) & $29.82 \pm 13.02$ & Spherical & $20.91 \pm 2.91$ \\
\hline wt ratio $1: 11$ and mole ratio $1: 2$ with SDS (at CMC) & $13.23 \pm 4.45$ & Spherical & $23.73 \pm 3.49$ \\
\hline wt ratio $1: 11$ and mole ratio $1: 2$ with SDS (at $2.5 \mathrm{CMC}$ ) & $25.04 \pm 5.48$ & Spherical & $44.01 \pm 9.14$ \\
\hline wt ratio $1: 11$ and mole ratio $1: 2$ with SDS (at 10CMC) & $45.12 \pm 6.02$ & Spherical & $26.44 \pm 7.16$ \\
\hline wt ratio $1: 11$ and mole ratio $1: 2$ with Triton $\mathrm{X}-100$ (at CMC) & $1289.43 \pm 81.14$ & Spherical & $21.37 \pm 3.05$ \\
\hline wt ratio $1: 11$ and mole ratio $1: 2$ with Triton $\mathrm{X}-100$ (at $2.5 \mathrm{CMC}$ ) & $1879.49 \pm 13.87$ & Spherical & $56.77 \pm 5.54$ \\
\hline wt ratio $1: 11$ and mole ratio $1: 2$ with Triton $\mathrm{X}-100$ (at $3.5 \mathrm{CMC}$ ) & $328.69 \pm 35.90$ & Spherical & $36.48 \pm 4.30$ \\
\hline wt ratio $1: 11$ and mole ratio $1: 2$ with Triton $\mathrm{X}-100$ (at $5 \mathrm{CMC}$ ) & $298.92 \pm 1.49$ & Spherical & $33.95 \pm 4.07$ \\
\hline wt ratio $1: 11$ and mole ratio $1: 2$ with Triton $\mathrm{X}-100$ (at 10CMC) & $238.87 \pm 4.04$ & Spherical & $30.28 \pm 3.62$ \\
\hline
\end{tabular}

2.5CMC showed the smallest particle size of $24.46 \pm 2.35 \mathrm{~nm}$ since the electro-attractive force between the cationic CTAB surfactant and PSS $^{-}$disturbs the formation of PSS micelles. ${ }^{53}$
For the anionic surfactant SDS at 2.5CMC, the particle size of PEDOT:PSS is $44.01 \pm 9.14 \mathrm{~nm}$, and SDS can repel and replace PSS $^{-}$; thus, disturbing the formation of PSS micelles. ${ }^{37}$ For the
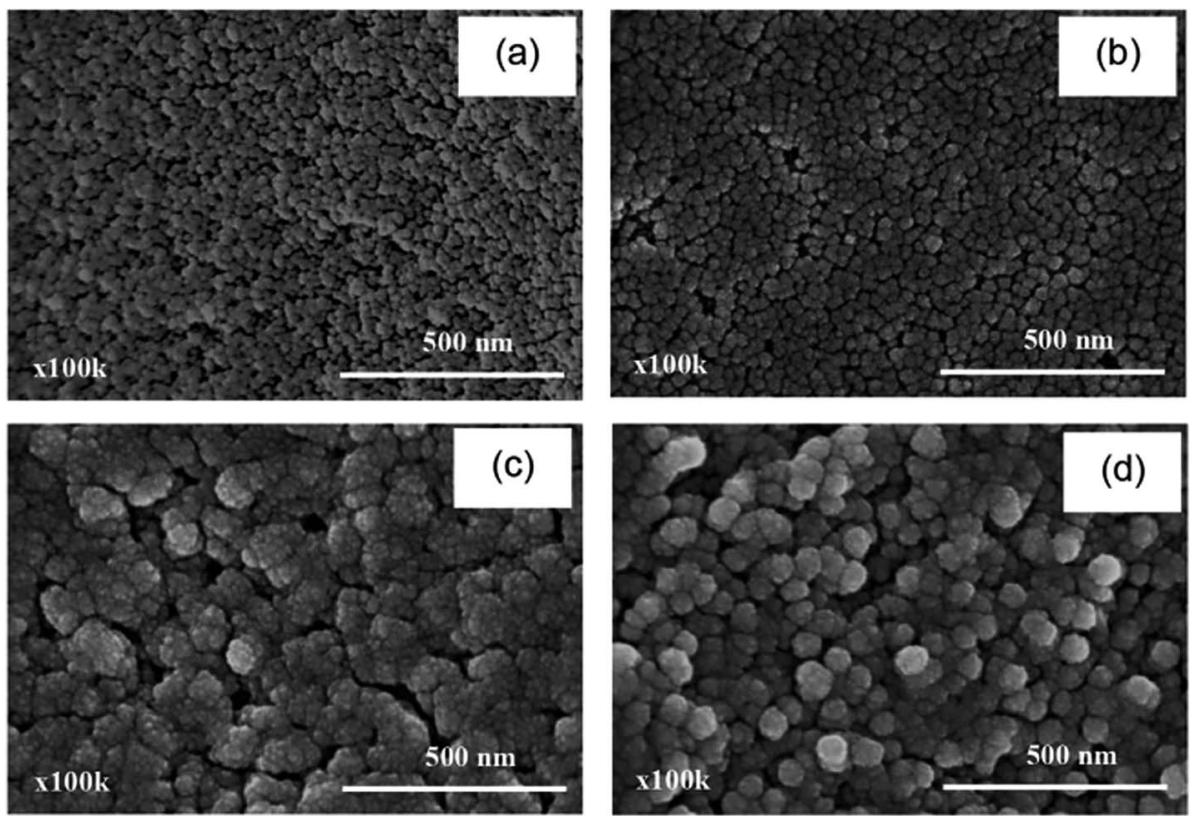

Fig. 6 PEDOT:PSS surface morphology at the EDOT : PSS weight ratio of $1: 11$ and EDOT : $\mathrm{Na}_{2} \mathrm{~S}_{2} \mathrm{O}_{8}$ mole ratio of $1: 2$ using various surfactant types: (a) no surfactant, (b) CTAB (2.5CMC), (c) SDS (2.5CMC), and (d) Triton X-100 (2.5CMC). 
non-ionic surfactant Triton X-100 at 2.5CMC, the particle size of PEDOT:PSS was the largest at $56.77 \pm 5.54 \mathrm{~nm}$ since Triton $\mathrm{X}$ 100 interferes with the PSS micelle formation. Triton X-100 consists of a large ethoxy chain acting as a bulky polar head group, which can separate the $\mathrm{SO}_{3}{ }^{-}$groups of the PSS micelle; thus, reducing the electrostatic repulsive interaction, leading to an increase in the PSS micelle size. ${ }^{\mathbf{6 0}}$

The effect of surfactant concentration at the EDOT: PSS weight ratio of $1: 11$ and EDOT $: \mathrm{Na}_{2} \mathrm{~S}_{2} \mathrm{O}_{8}$ mole ratio of $1: 2$ on the PEDOT:PSS morphology is shown in Table 3. The shapes of PEDOT:PSS are still spherical. At the CMC, the surfactants form micelles, which are unstable and can disturb the interaction between PEDOT and PSS; thus, the particle sizes are larger than PEDOT:PSS without a surfactant. ${ }^{30}$ Above the CMC, surfactants are prone to interact with the PSS molecules, and thus the formation of PSS micelles is interrupted, leading to larger particle sizes.

\subsection{Thermal stability}

The thermal stability of PEDOT:PSS was investigated by TG-DTA under an $\mathrm{N}_{2}$ flow, as shown in Fig. 7, and the onset decomposition temperatures $\left(T_{\mathrm{d} \text {,onset }}\right)$ of PEDOT:PSS with different surfactant systems were measured. The $T_{\mathrm{d} \text {,onset }}$ of PEDOT:PSS at the EDOT : PSS weight ratio of $1: 11$ and EDOT : $\mathrm{Na}_{2} \mathrm{~S}_{2} \mathrm{O}_{8}$ mole ratio of $1: 2$ without surfactant was $499^{\circ} \mathrm{C}$ and the char yield at $790{ }^{\circ} \mathrm{C}$ was $53.43 \%$. The $T_{\mathrm{d} \text {,onset }}$ of PEDOT:PSS synthesized under the same conditions using Triton X-100 at 2.5CMC was $492.97{ }^{\circ} \mathrm{C}$ and the char yield at $790{ }^{\circ} \mathrm{C}$ was $44.05 \%$. For the CTAB system (2.5CMC), the $T_{\mathrm{d} \text {,onset }}$ of PEDOT:PSS was $407.98{ }^{\circ} \mathrm{C}$ and the char yield at $790{ }^{\circ} \mathrm{C}$ was $51.62 \%$. For the SDS system (2.5CMC), the $T_{\mathrm{d} \text {,onset }}$ of PEDOT:PSS was $413.52{ }^{\circ} \mathrm{C}$ and the char yield at $790{ }^{\circ} \mathrm{C}$ was $50.52 \%$. The PEDOT:PSS with the surfactants possessed lower $T_{\mathrm{d} \text {,onset }}$ and \% char yield values than that without surfactant. Thus, PEDOT:PSS with the surfactants possessed higher thermal degradation values because the surfactants disturbed the polymerization of PEDOT:PSS, resulting in a shorter conjugated polymer. ${ }^{61}$ For the PEDOT:PSS

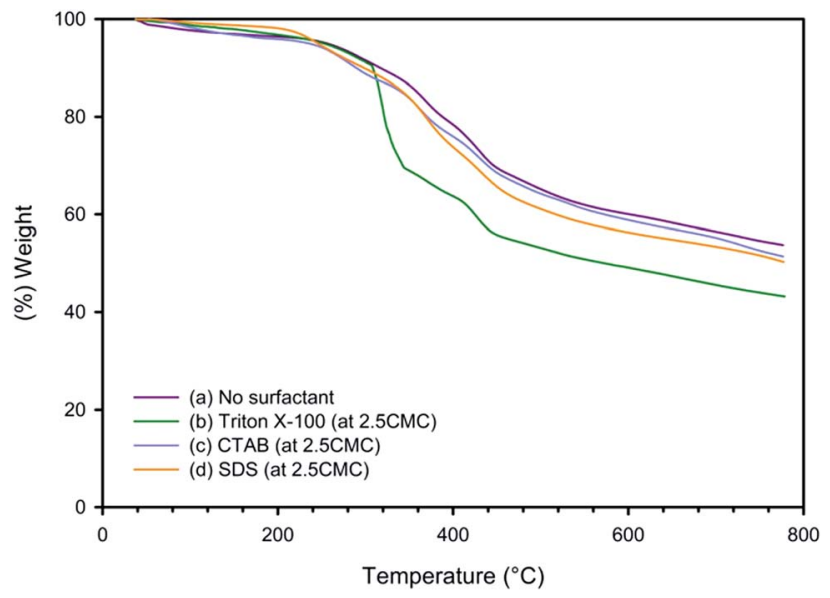

Fig. 7 TGA spectra of PEDOT:PSS at the EDOT : PSS weight ratio of $1: 11$ and EDOT: $\mathrm{Na}_{2} \mathrm{~S}_{2} \mathrm{O}_{8}$ mole ratio of $1: 2$ : (a) no surfactant, (b) Triton X-100 (2.5CMC), (c) CTAB (2.5CMC) and (d) SDS (2.5CMC).

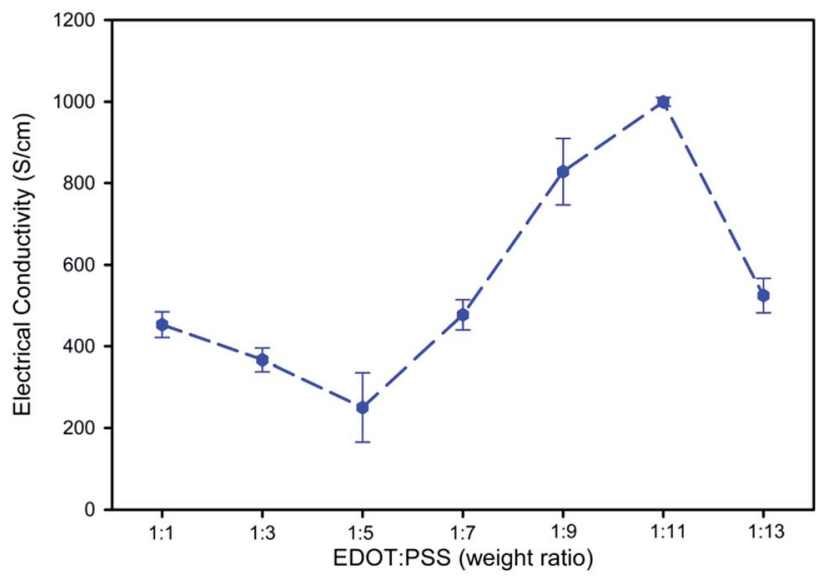

Fig. 8 Electrical conductivity of PEDOT:PSS at the EDOT: $\mathrm{Na}_{2} \mathrm{~S}_{2} \mathrm{O}_{8}$ mole ratio of $1: 1$ and at various EDOT : PSS weight ratios.

without surfactant and with Triton X-100, CTAB, and SDS, the thermograms show four decomposition stages: the first stage is the decomposition of water and moisture in the temperature range of $100-180^{\circ} \mathrm{C}$; the second stage is the decomposition of the side chains in the temperature range of $180-320{ }^{\circ} \mathrm{C}$; the third stage exhibits the decomposition of PSS in the temperature range of $320-400{ }^{\circ} \mathrm{C}$; and the last stage illustrates the decomposition of PEDOT (main chain) in the temperature range of $400-790{ }^{\circ} \mathrm{C}^{23}$ For the effect of EDOT : $\mathrm{Na}_{2} \mathrm{~S}_{2} \mathrm{O}_{8}$ mole ratio at the EDOT : PSS weight ratio of $1: 11$, the TGA thermograms were nearly the same as the above results.

\subsection{Electrical conductivity}

The electrical conductivity of the PEDOT:PSS synthesized at the EDOT : $\mathrm{Na}_{2} \mathrm{~S}_{2} \mathrm{O}_{8}$ mole ratio of $1: 1$ and at various EDOT : PSS weight ratios is shown in Fig. 8. For EDOT : PSS weight ratios between $1: 1$ and $1: 5$, the electrical conductivity of PEDOT:PSS decreased from $452.81 \pm 31.59$ to $250.23 \pm 85.13 \mathrm{~S} \mathrm{~cm}^{-1}$ since the PSS amount is low and it may act as an insulator. ${ }^{20}$ At EDOT : PSS weight ratios between $1: 5$ and $1: 11$, the electrical

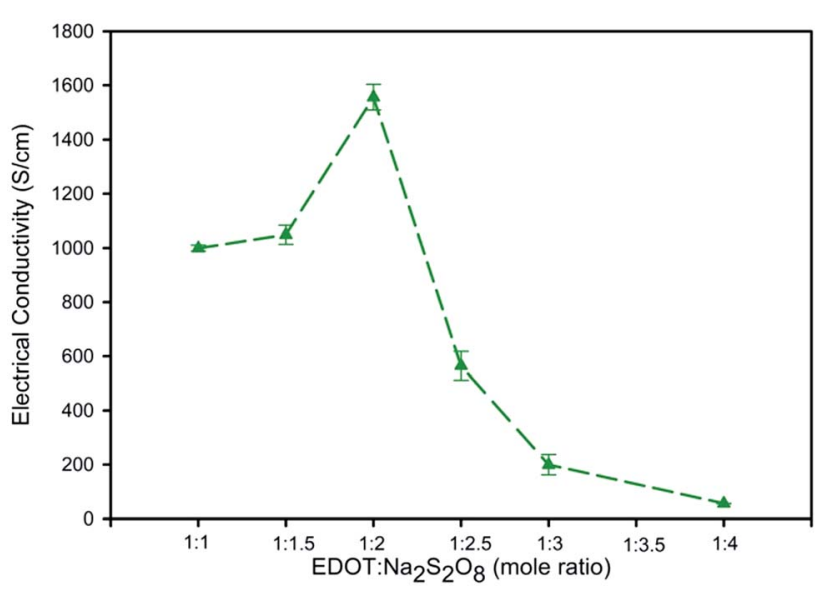

Fig. 9 Electrical conductivity of PEDOT:PSS at the EDOT : PSS weight ratio of 1 : 11 and at various EDOT : $\mathrm{Na}_{2} \mathrm{~S}_{2} \mathrm{O}_{8}$ mole ratios. 
conductivity of PEDOT:PSS increased from $250.23 \pm 85.13$ to $999.74 \pm 10.86 \mathrm{~S} \mathrm{~cm}^{-1}$ since PSS acts effectively as a dopant. ${ }^{13}$ The electrical conductivity increases due to an increase in the number of charge carriers..$^{52}$ This finding is consistent with the increase in $\% \mathrm{PSS}^{-}$and $\% \mathrm{SO}_{4}{ }^{2-}$ from XPS and the decrease in the band gap energy from UV-Vis. However, at the EDOT : PSS weight ratio of $1: 13$, the electrical conductivity of PEDOT:PSS decreased to $524.23 \pm 42.29 \mathrm{~S} \mathrm{~cm}^{-1}$ due to over-doping. ${ }^{51}$ Hence, the EDOT : PSS weight ratio of $1: 11$ is optimal owing to the highest electrical conductivity obtained (999.74 \pm $10.86 \mathrm{~S} \mathrm{~cm}^{-1}$ ).

The electrical conductivity of PEDOT:PSS using the EDOT : PSS weight ratio of $1: 11$ at various EDOT : $\mathrm{Na}_{2} \mathrm{~S}_{2} \mathrm{O}_{8}$ mole ratios is shown in Fig. 9. As the EDOT : $\mathrm{Na}_{2} \mathrm{~S}_{2} \mathrm{O}_{8}$ mole ratio increased from $1: 1$ to $1: 2$, the electrical conductivity of PEDOT:PSS increased from $999.74 \pm 10.86$ to $1556.85 \pm$ $46.84 \mathrm{~S} \mathrm{~cm}^{-1}$ since $\mathrm{SO}_{4}{ }^{2-}$ from the oxidant may also act as a dopant ${ }^{12}$ by interacting with the oxidized PEDOT chain. This finding is consistent with the $\% \mathrm{SO}_{4}{ }^{2-}$ increase from XPS, the decrease in band gap energy, and the low PSSNa amount. At EDOT : $\mathrm{Na}_{2} \mathrm{~S}_{2} \mathrm{O}_{8}$ mole ratios above $1: 2$, the electrical conductivity of PEDOT:PSS decreased from $1556.85 \pm 46.84 \mathrm{~S} \mathrm{~cm}^{-1}$ to $55.61 \pm 0.10 \mathrm{~S} \mathrm{~cm}^{-1}$ because $\mathrm{Na}^{+}$ions from the oxidant can react with PSS $^{-}$to form PSSNa, which reduces the amount of PSS

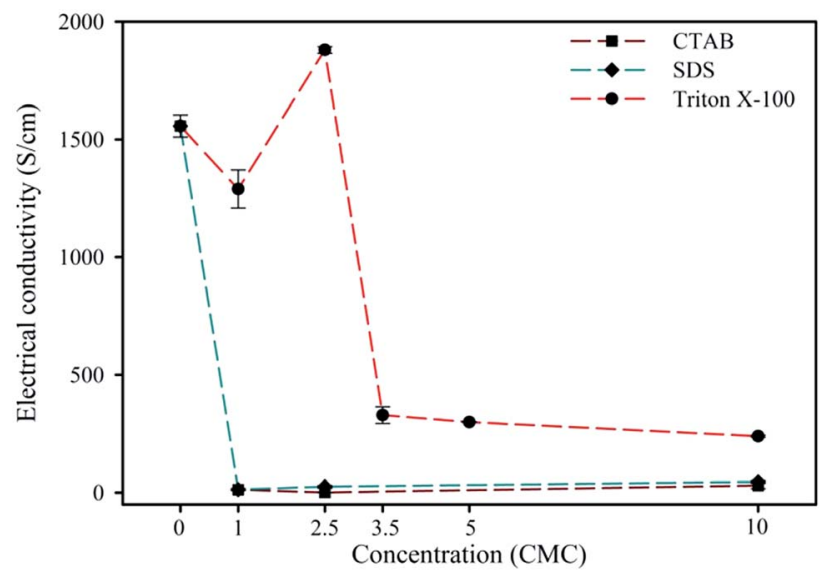

Fig. 10 Electrical conductivity of PEDOT:PSS at the EDOT: PSS weight ratio of $1: 11$ and EDOT: $\mathrm{Na}_{2} \mathrm{~S}_{2} \mathrm{O}_{8}$ mole ratio of $1: 2$ with various surfactant types and concentrations. available to dope PEDOT, leading to a decrease in electrical conductivity. ${ }^{42}$ The increase in PSSNa was identified at the EDOT : $\mathrm{Na}_{2} \mathrm{~S}_{2} \mathrm{O}_{8}$ mole ratios of $1: 3$ and $1: 4$ by XPS and XRD. Moreover, the decrease in electrical conductivity is related to the increase in the band gap energy. Thus, the EDOT: $\mathrm{Na}_{2} \mathrm{~S}_{2} \mathrm{O}_{8}$ mole ratio of $1: 2$ is optimal to acquire the high PEDOT:PSS electrical conductivity of $1556.85 \pm 46.84 \mathrm{~S} \mathrm{~cm}^{-1}$, as confirmed by the low band gap energy of $1.90 \mathrm{eV}$ compared to other EDOT : $\mathrm{Na}_{2} \mathrm{~S}_{2} \mathrm{O}_{8}$ mole ratios.

The electrical conductivity of PEDOT:PSS synthesized using the EDOT : PSS weight ratio of $1: 11$ and EDOT : $\mathrm{Na}_{2} \mathrm{~S}_{2} \mathrm{O}_{8}$ mole ratio of $1: 2$ with various surfactant types and concentrations is shown in Fig. 10. The CTAB and SDS systems are not suitable to synthesize PEDOT:PSS since the electrical conductivity is 100 times lower than that of PEDOT:PSS without these two surfactants. CTAB can react with the PSS chain; ${ }^{53}$ whereas, SDS can replace PSS. $^{37}$ Moreover, these two systems induce a decrease in the amount of dopant $\left(\% \mathrm{SO}_{3}{ }^{-}\right.$of PSS and \% $\mathrm{SO}_{4}{ }^{2-}$ of $\mathrm{Na}_{2} \mathrm{~S}_{2} \mathrm{O}_{8}$ ), as confirmed by XPS and the increase in band gap energy from $1.90 \mathrm{eV}$ to $3.50 \mathrm{eV}$ for CTAB and $1.90 \mathrm{eV}$ to $3.00 \mathrm{eV}$ for SDS. For Triton X-100, it can react with both PEDOT and the PSS chains, and can form a TX-PSS complex, which can be easily removed by methanol washing, ${ }^{54}$ resulting in the removal of PSS ${ }^{-}$acting as a dopant and PSSNa as a salt. This suggests that Triton X-100 reduces the PEDOT and PSS interaction as well as the PSSNa amount. From the XPS result, the decrease in the amount of PSSNa amount was clearly observed with an increase Triton X-100 concentration together with a decrease in the amount of dopant $\left(\% \mathrm{SO}_{3}{ }^{-}\right.$of PSS and \% $\mathrm{SO}_{4}{ }^{2-}$ of $\mathrm{Na}_{2} \mathrm{~S}_{2} \mathrm{O}_{8}$ ). However, using Triton X-100 at 2.5CMC provides a suitable condition for the removal of PSSNa since the highest electrical conductivity of $1879.49 \pm 13.87 \mathrm{~S} \mathrm{~cm}^{-1}$ with the lowest band gap energy of $1.80 \mathrm{eV}$ were obtained, while the dopant amount remained high. A higher Triton X100 concentration tended to remove the dopants, although PSSNa was preferentially eliminated.

To confirm the electrical conductivity of the synthesized PEDOT:PSS as measured by a custom-built 2-point probe, the electrical conductivity of graphite (particle size $<20 \mu \mathrm{m}$, Sigma Aldrich) and multi-walled carbon nanotubes (specific of diameter of 30-50 nm, >95 wt\% purity, Alphanano Technology Co., Ltd.) was also measured by using the same equipment and the same sample thickness. The obtained electrical conductivity of

Table 4 Comparison of the electrical conductivity, particle shape, and size of various PEDOT:PSS particles

\begin{tabular}{|c|c|c|c|c|c|}
\hline PEDOT:PSS & $\mathrm{Fe}\left(\mathrm{NO}_{3}\right)_{3} \cdot 9 \mathrm{H}_{2} \mathrm{O}$ & 9.90 & - & - & Qi et al., 1998 \\
\hline & $\mathrm{FeCl}_{3}$ & 0.006 & - & - & \\
\hline PEDOT:PSS & $\mathrm{Fe}\left(\mathrm{NO}_{3}\right)_{3} \cdot 9 \mathrm{H}_{2} \mathrm{O}$ & 1.50 & - & - & Lefebvre et al., 1999 \\
\hline PEDOT:PSS & $\mathrm{Fe}\left(\mathrm{NO}_{3}\right)_{3} \cdot 9 \mathrm{H}_{2} \mathrm{O}$ & 4.30 & - & - & Dai et al., 2008 \\
\hline PEDOT:PSS & $\mathrm{Na}_{2} \mathrm{~S}_{2} \mathrm{O}_{8}$ & 1556.85 & Spherical & 19.84 & Present work \\
\hline PEDOT:PSS with Triton X-100 at 2.5CMC & $\mathrm{Na}_{2} \mathrm{~S}_{2} \mathrm{O}_{8}$ & 1879.49 & Spherical & 56.77 & \\
\hline
\end{tabular}


(a)

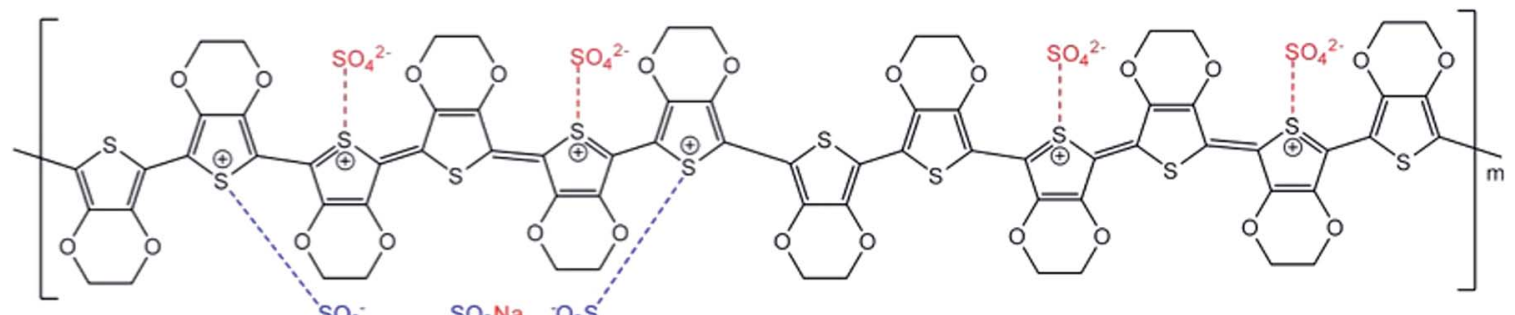

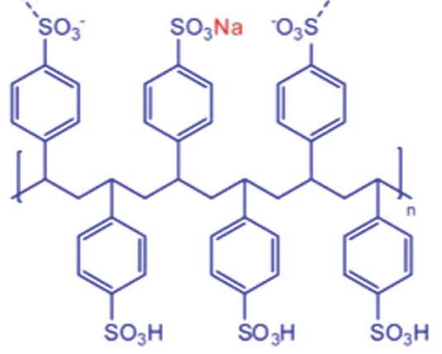

(b)

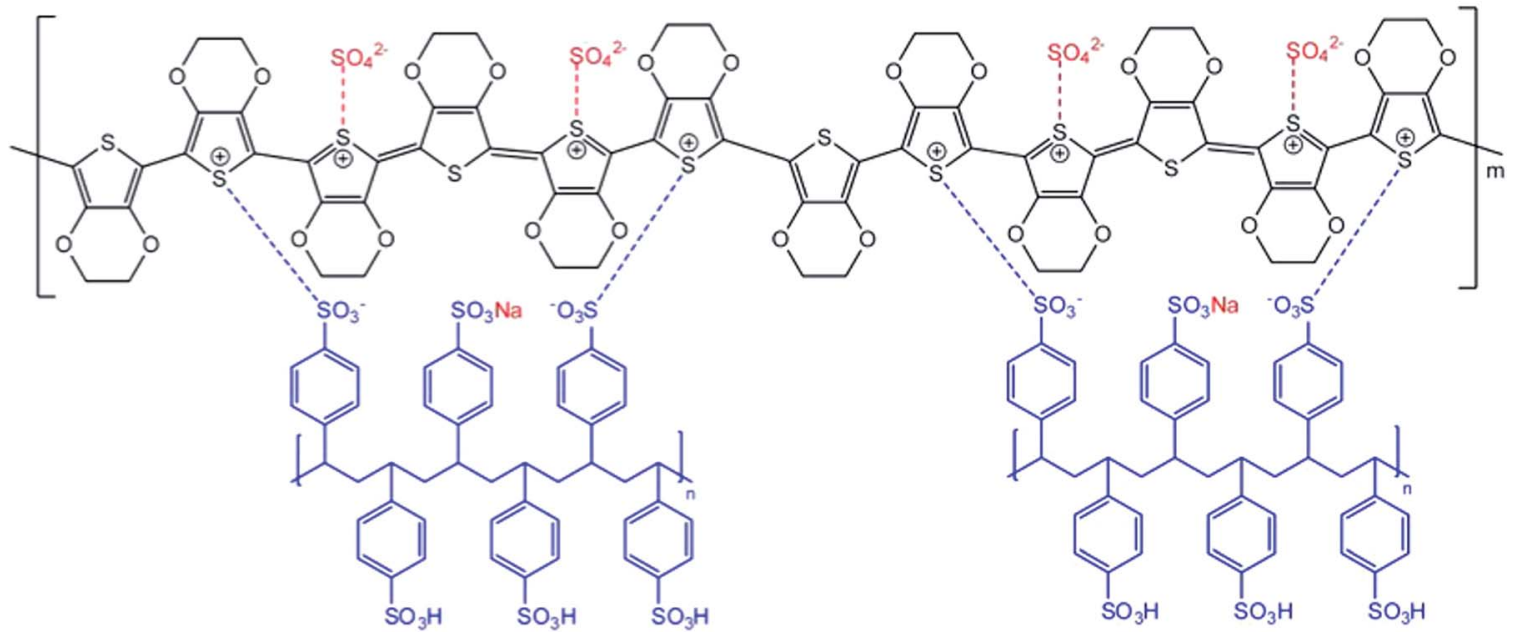

(c)

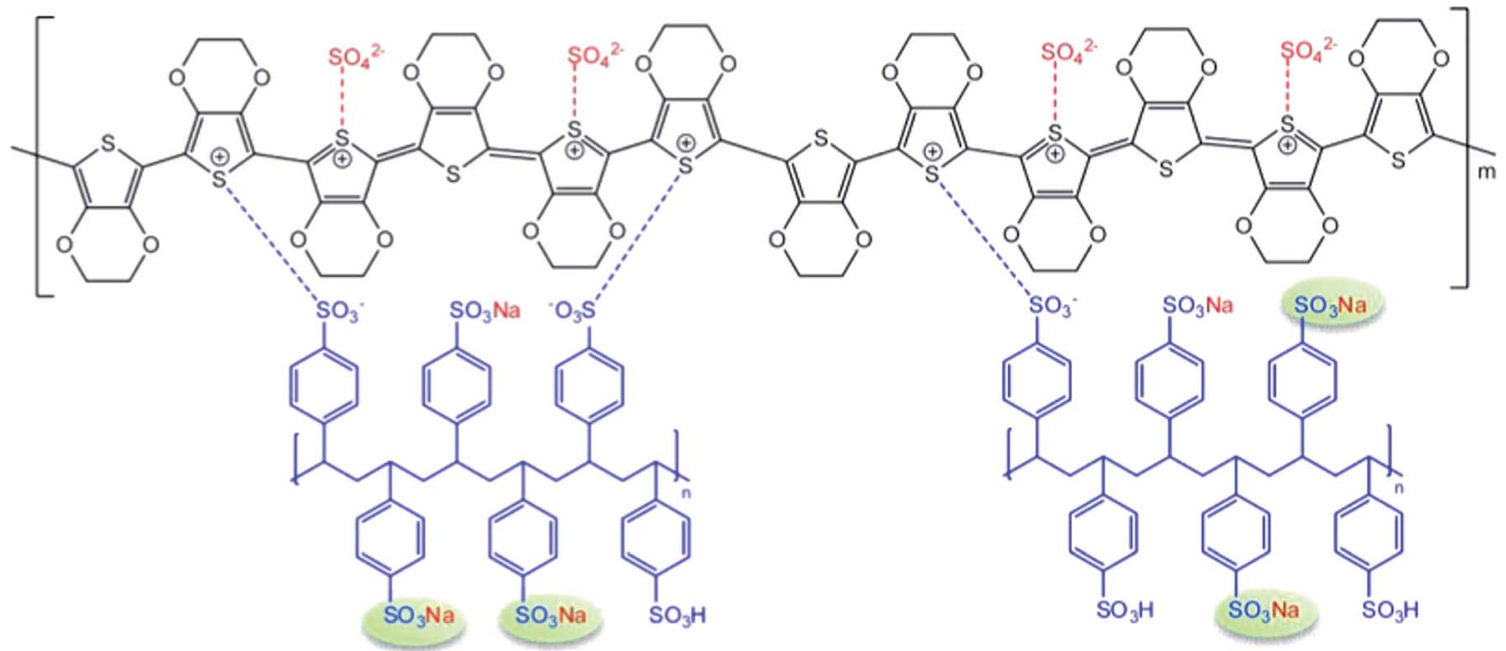

Scheme 2 Proposed interaction of PEDOT:PSS at the EDOT : $\mathrm{Na}_{2} \mathrm{~S}_{2} \mathrm{O}_{8}$ mole ratio of $1: 1$ and various EDOT : PSS weight ratios: at an EDOT : PSS weight ratio (a) lower than $1: 11$, (b) $1: 11$, where more PSS interact, and (c) higher than $1: 11$ with a higher PSSNa amount to reduce the doping sites on PSS.

graphite was $14282.18 \mathrm{~S} \mathrm{~cm}^{-1}$ (ref. 62) and MWCNT was $1589.17 \mathrm{~S} \mathrm{~cm}^{-1},{ }^{63}$ consistent with the data from previous work. It should be noted that the electrical conductivity of the synthesized PEDOT:PSS powder was in the same range as that of MWCNT.
The related works of the synthesized PEDOT:PSS powder are tabulated in Table 4, where Qi and co-workers (1998) prepared PEDOT:PSS via chemical oxidative polymerization. They used EDOT and PSSNa as the reactants and $\mathrm{Fe}\left(\mathrm{NO}_{3}\right)_{3} \cdot 9 \mathrm{H}_{2} \mathrm{O}$ as the oxidant. The reaction time was $2 \mathrm{~h}$ to obtain a dark blue 
(a)

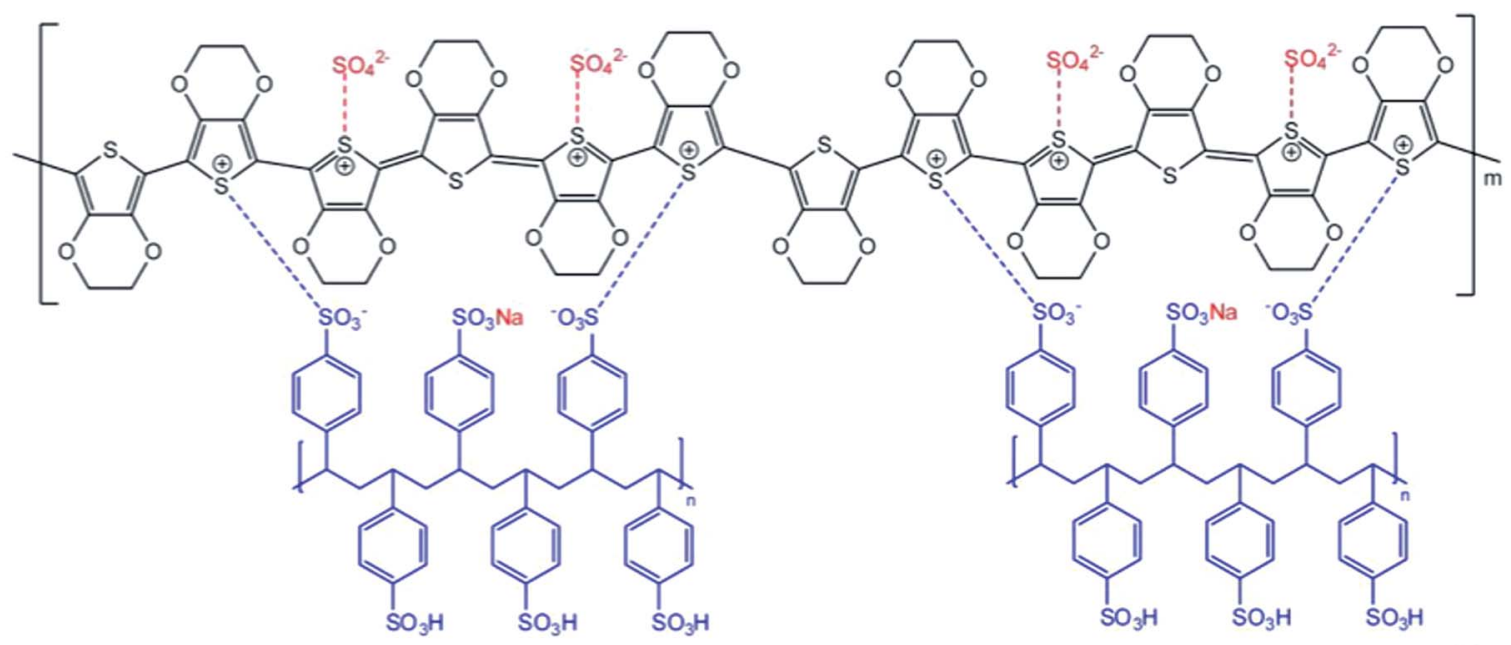

(b)

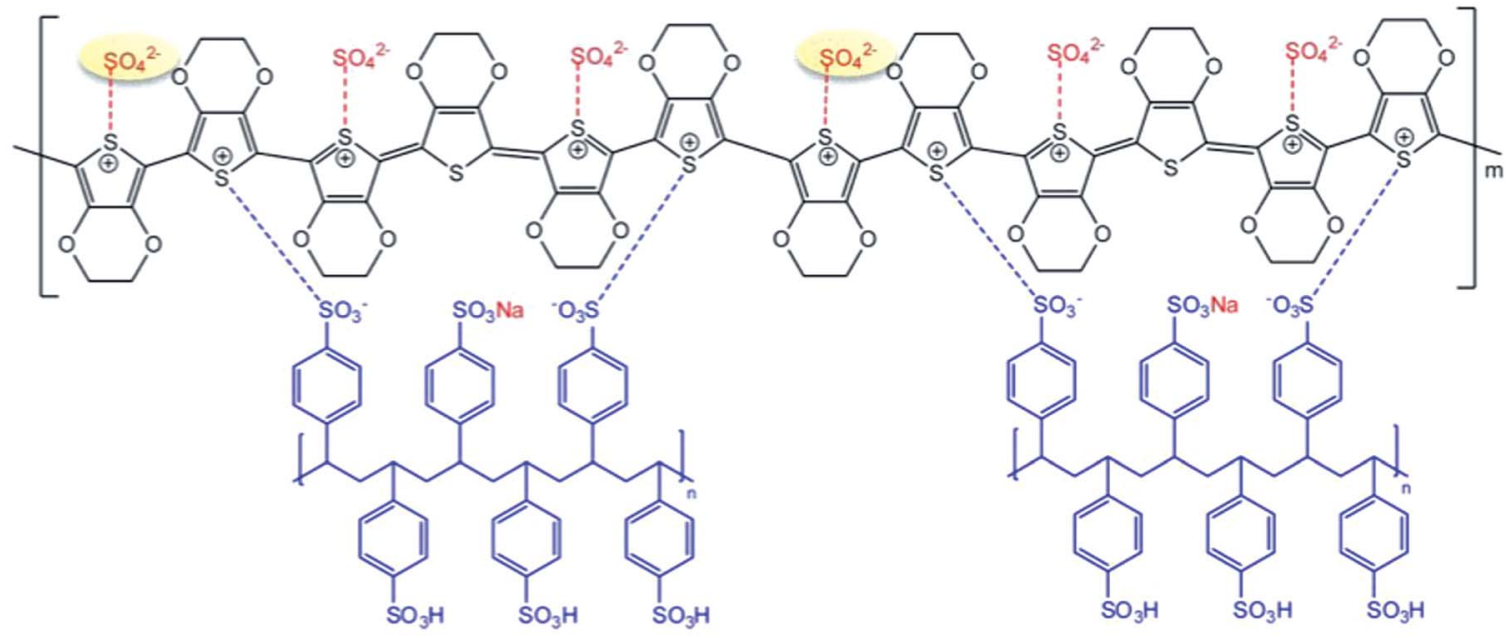

(c)

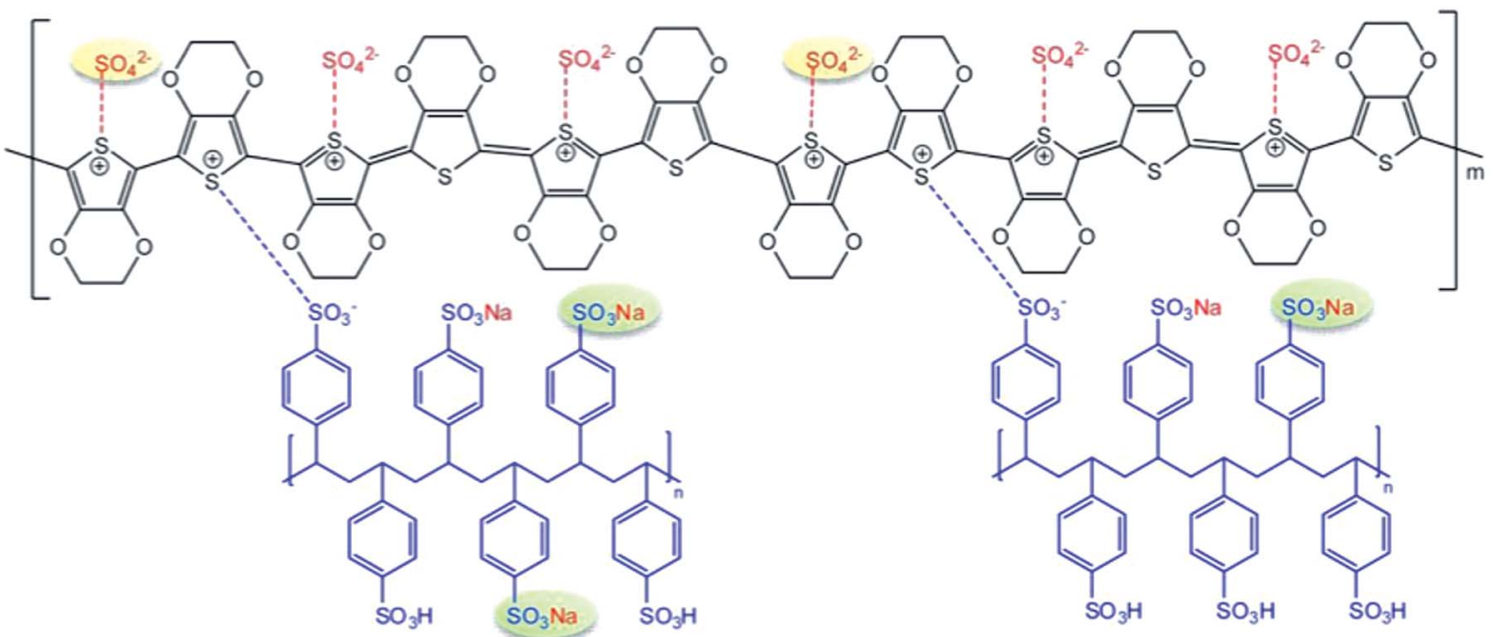

Scheme 3 Proposed structure of PEDOT:PSS at the EDOT:PSS weight ratio of $1: 11$ and at various EDOT: $\mathrm{Na}_{2} \mathrm{~S}_{2} \mathrm{O}_{8}$ mole ratios: at an EDOT : $\mathrm{Na}_{2} \mathrm{~S}_{2} \mathrm{O}_{8}$ mole ratio (a) lower than $1: 2$, (b) $1: 2$, where $\mathrm{SO}_{4}{ }^{2-}$ acts as a secondary dopant and (c) higher than $1: 2$, where a higher PSSNa amount is generated.

solution. The electrical conductivity of PEDOT:PSS was $9.9 \mathrm{~S} \mathrm{~cm}^{-1}{ }^{64}$ Lefebvre et al. synthesized PEDOT:PSS using a mixed solvent of acetonitrile : water at a ratio of $1: 1$. EDOT and NaPSS were used as the reactants and $\mathrm{Fe}\left(\mathrm{NO}_{3}\right)_{3} \cdot 9 \mathrm{H}_{2} \mathrm{O}$ and $\mathrm{FeCl}_{3}$ were used the oxidants. The electrical conductivity value at the EDOT: $\mathrm{Fe}\left(\mathrm{NO}_{3}\right)_{3} \cdot 9 \mathrm{H}_{2} \mathrm{O}$ mole ratio of $1: 5$ was $2.50 \mathrm{~S} \mathrm{~cm}^{-1}$, while at the EDOT : $\mathrm{FeCl}_{3}$ mole ratio of $1: 10$ it was $0.006 \mathrm{~S} \mathrm{~cm}^{-1} .^{24}$ Lefebvre et al. prepared PEDOT:PSS using $\mathrm{Fe}\left(\mathrm{NO}_{3}\right)_{3} \cdot 9 \mathrm{H}_{2} \mathrm{O}$ as the oxidant and a mixture of acetonitrile :water at a ratio of $1: 1$ as the solvent. Using the 
(a)

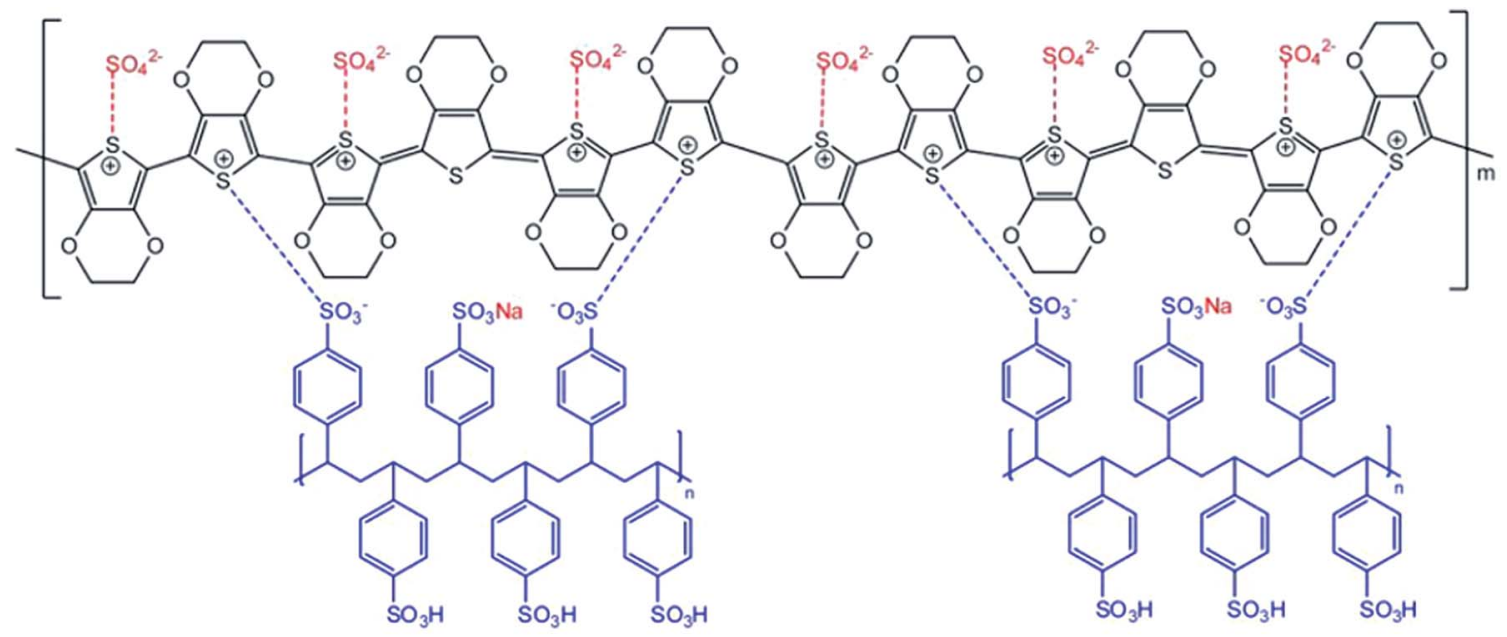

(b)

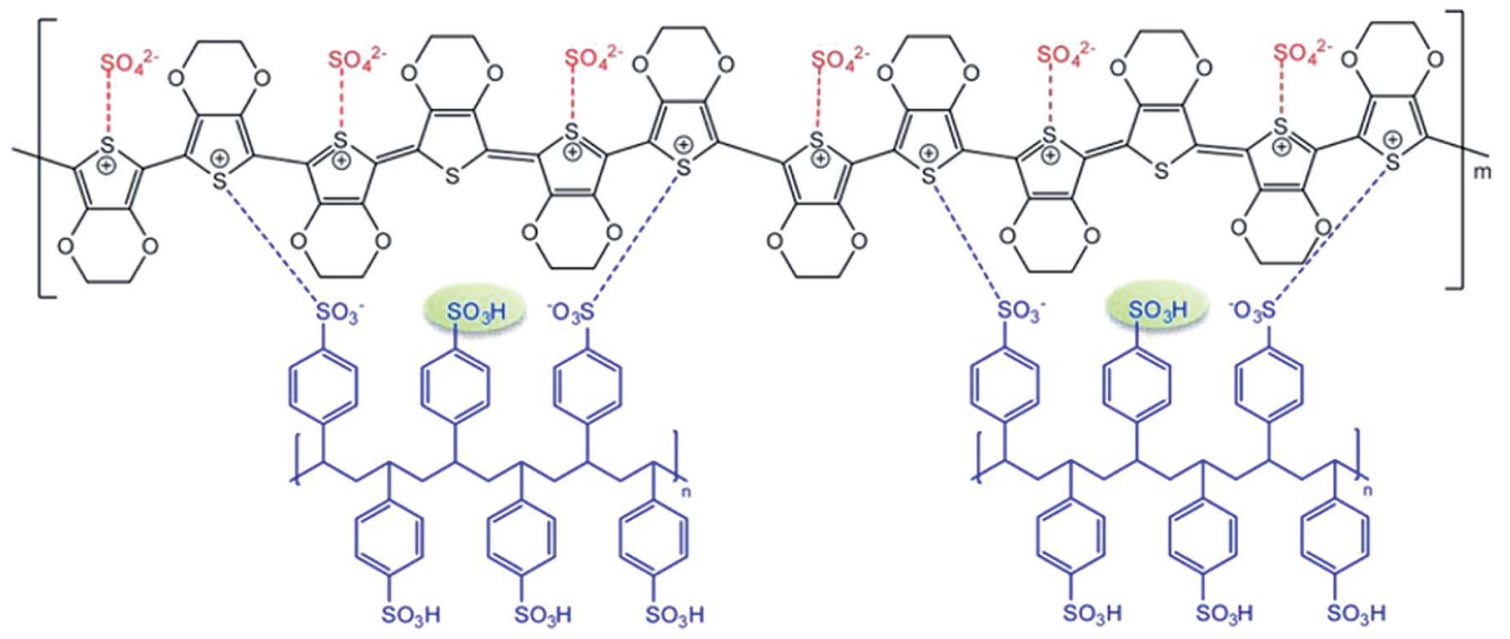

Scheme 4 Proposed structure of PEDOT:PSS at the EDOT : PSS weight ratio of $1: 11$ and EDOT : $\mathrm{Na}_{2} \mathrm{~S}_{2} \mathrm{O}_{8}$ mole ratio of $1: 2$ : (a) no surfactant; and (b) Triton X-100, where PSSNa amount is reduced through methanol washing.

EDOT : $\mathrm{Fe}\left(\mathrm{NO}_{3}\right)_{3} \cdot 9 \mathrm{H}_{2} \mathrm{O}$ mole ratio of $1: 10$, the electrical conductivity was $1.50 \mathrm{~S} \mathrm{~cm}^{-1} .^{21}$ Dai et al., 2008, synthesized PEDOT:PSS using $\mathrm{Fe}\left(\mathrm{NO}_{3}\right)_{3} \cdot 9 \mathrm{H}_{2} \mathrm{O}$ as the oxidant and water as the solvent and the reaction time was $24 \mathrm{~h}$ at room temperature, giving an electrical conductivity value of $4.3 \mathrm{~S} \mathrm{~cm}^{-1}{ }^{65}$ Wichiansee and co-worker prepared PEDOT:PSS by mixing EDOT, PSS, and $\mathrm{Na}_{2} \mathrm{~S}_{2} \mathrm{O}_{8}$ in distilled water. Subsequently, $\mathrm{Fe}_{2}\left(\mathrm{SO}_{4}\right)_{3}$ was added to the solution and it was stirred continuously for $24 \mathrm{~h}$. The electrical conductivity was $27.50 \mathrm{~S} \mathrm{~cm}^{-1}$. $^{22}$ Chanthanont and co-workers, 2013, synthesized PEDOT:PSS using an EDOT : PSS mole ratio of $1: 1$ in distilled water. $\mathrm{Na}_{2} \mathrm{~S}_{2} \mathrm{O}_{8}$ was used as the oxidant and $\mathrm{Fe}_{2}\left(\mathrm{SO}_{4}\right)_{3}$ was added to the solution and stirred vigorously for $24 \mathrm{~h}$. The electrical conductivity was $11.69 \mathrm{~S} \mathrm{~cm}^{-1}$.23

\subsection{Interaction of PEDOT:PSS and dopants including PSSNa}

For the effect of EDOT : PSS weight ratio, at the EDOT : $\mathrm{Na}_{2} \mathrm{~S}_{2} \mathrm{O}_{8}$ mole ratio of $1: 1$, PSS as the dopant reacts with PEDOT, as shown in Scheme $2 .{ }^{13}$ At an EDOT : PSS weight ratio lower than $1: 11$, as shown in Scheme 2(a), a small amount of PSS interacts with PEDOT, as confirmed by XPS. At the EDOT : PSS weight ratio of $1: 11$, as shown in Scheme 2(b), more PSS chains are available to dope the PEDOT chains. However, at a EDOT : PSS weight ratio above $1: 11$, as shown in Scheme 2(c), PSS also reacts with $\mathrm{Na}^{+}$from $\mathrm{Na}_{2} \mathrm{~S}_{2} \mathrm{O}_{8}$ to form PSSNa on PSS, as confirmed by XPS and XRD. The presence of PSSNa reduces the number of doping sites on PSS. Hence, the EDOT : PSS weight ratio of $1: 11$ is the optimal condition because of the highest electrical conductivity $\left(999.74 \pm 10.86 \mathrm{~S} \mathrm{~cm}^{-1}\right)$ and lowest UVVis energy gap $(2.67 \mathrm{eV})$. This shows that only a proper amount of PSS increases the number of charge carriers, resulting in an increase in the electrical conductivity. ${ }^{52}$

The PEDOT:PSS synthesized at the EDOT : PSS weight ratio of $1: 11$ and various EDOT $: \mathrm{Na}_{2} \mathrm{~S}_{2} \mathrm{O}_{8}$ mole ratios is demonstrated in Scheme 3. At an EDOT: $\mathrm{Na}_{2} \mathrm{~S}_{2} \mathrm{O}_{8}$ mole ratio lower than $1: 2$, as shown in Scheme $3(\mathrm{a}), \mathrm{SO}_{4}{ }^{2-}$ acts as an oxidant and dopant ${ }^{12}$ and it interacts with the PEDOT chains, but a small number of $\mathrm{SO}_{4}{ }^{2-}$ ions are available to interact with PEDOT to generate a small number of charge carriers, resulting in low electrical conductivity. ${ }^{52}$ In addition, $\mathrm{Na}^{+}$from $\mathrm{Na}_{2} \mathrm{~S}_{2} \mathrm{O}_{8}$ also reacts with PSS to form PSSNa, as verified by XPS and XRD. 
At the EDOT : $\mathrm{Na}_{2} \mathrm{~S}_{2} \mathrm{O}_{8}$ mole ratio of $1: 2$, as shown in Scheme $3(\mathrm{~b})$, more $\mathrm{SO}_{4}{ }^{2-}$ ions are available to interact with PEDOT, as confirmed by XPS, while the PSSNa amount does not significantly increase. At an EDOT : $\mathrm{Na}_{2} \mathrm{~S}_{2} \mathrm{O}_{8}$ mole ratio above $1: 2$, as shown in Scheme 3(c), more $\mathrm{SO}_{4}{ }^{2-}$ ions interact with PEDOT, but at the expense of more $\mathrm{Na}^{+}$ions from $\mathrm{Na}_{2} \mathrm{~S}_{2} \mathrm{O}_{8}$ reacting with PSS to form PSSNa, as confirmed by XPS and XRD. Therefore, the EDOT : $\mathrm{Na}_{2} \mathrm{~S}_{2} \mathrm{O}_{8}$ mole ratio of $1: 2$ is the optimal condition since it provides the highest electrical conductivity (1556.85 \pm $46.84 \mathrm{~S} \mathrm{~cm}^{-1}$ ) and lowest energy gap of $1.90 \mathrm{eV}$.

At the EDOT : PSS weight ratio of $1: 11$ and EDOT : $\mathrm{Na}_{2} \mathrm{~S}_{2} \mathrm{O}_{8}$ mole ratio of $1: 2$, the interactions are shown in Scheme 4(a) without a surfactant and in Scheme 4(b) with Triton X-100. As shown in Scheme 4(b), Triton X-100 reacts with PSS and it reduces the PEDOT and PSS interaction and the PSSNa amount, which can be easily removed by methanol washing, ${ }^{54}$ as verified by XPS. Hence, using Triton X-100 at 2.5CMC yielded the highest electrical conductivity of $1879.49 \pm 13.87 \mathrm{~S} \mathrm{~cm}^{-1}$ with the lowest energy gap of $1.80 \mathrm{eV}$.

\section{Conclusion}

PEDOT:PSS was successfully synthesized via chemical oxidative polymerization with high electrical conductivity and a systematic route was used to investigate the effects of EDOT : PSS weight ratio, EDOT : $\mathrm{Na}_{2} \mathrm{~S}_{2} \mathrm{O}_{8}$ mole ratio, and surfactant type and concentration on its properties. The EDOT : PSS weight ratio of $1: 11$ provided the highest $\mathrm{PSS}^{-}$dopant amount to interact with PEDOT. For the effect of EDOT : $\mathrm{Na}_{2} \mathrm{~S}_{2} \mathrm{O}_{8}$ mole ratio, the EDOT : $\mathrm{Na}_{2} \mathrm{~S}_{2} \mathrm{O}_{8}$ mole ratio of $1: 2$ was the optimal condition since $\mathrm{SO}_{4}{ }^{2-}$ from the oxidant acting as a secondary dopant increased the number of charge carriers, resulting in the high electrical conductivity of $1556.85 \pm 46.84 \mathrm{~S} \mathrm{~cm}^{-1}$ and low energy gap of $1.90 \mathrm{eV}$. In the case of the three surfactant systems, Triton X-100 (2.5CMC) was the suitable surfactant to synthesize PEDOT:PSS, at the EDOT : PSS weight ratio of $1: 11$ and EDOT : $\mathrm{Na}_{2} \mathrm{~S}_{2} \mathrm{O}_{8}$ mole ratio of $1: 2$ because of the highest electrical conductivity of $1879.49 \pm 13.87 \mathrm{~S} \mathrm{~cm}^{-1}$ and the lowest energy gap of $1.80 \mathrm{eV}$. Triton X-100 molecules reduced the PEDOT and PSS interactions and the amount of PSSNa, which could be easily removed by methanol washing. The washing reduced the PSSNa amount on PSS, which then provided a higher number of doping sites on PSS. The particle shape of the PEDOT:PSS synthesized in all conditions were spherical. The particle size of PEDOT:PSS varied from $16.57 \pm 1.99$ to $56.77 \pm 5.54 \mathrm{~nm}$. The thermogravimetric analysis revealed that PEDOT:PSS with surfactants exhibited lower thermal stability than PEDOT:PSS without surfactant. The synthesis of PEDOT:PSS in this work provides guidance for the production and use of PEDOT:PSS particles in powder form with very high electrical conductivity, potentially suitable for many electronic applications such as drug delivery, thin film transistors, light emitting diodes, sensors, photovoltaics, and actuators.

\section{Conflicts of interest}

There are no conflicts to declare.

\section{Acknowledgements}

The authors are graceful for the scholarship from the Thailand Research Fund through the Royal Golden Jubilee PhD Program (RGJ PHD/0108/2559), the funding from the Conductive and Electroactive Polymer Research Unit, the Thailand Research Fund (TRF), and the Royal Thai Government.

\section{References}

1 T. H. Le, Y. Kim and H. Yoon, Polymers, 2017, 9, 150.

2 P. Kar, Doping in conjugated polymers, Scrivener Publishing LLC, Canada, 1st edn, 2013.

3 H. Shirakawa, E. J. Louis, A. G. MacDiarmid, C. K. Chiang and A. J. Heeger, J. Chem. Soc., Chem. Commun., 1997, 578580.

4 N. Hall, Chem. Commun., 2003, 1-4.

5 W. S. Huang, B. D. Humphrey and A. G. MacDiarmid, J. Chem. Soc., Faraday Trans. 1, 1986, 82, 2385-2400.

6 R. D. McCullough, R. D. Lowe, M. Jayaraman and D. L. Anderson, J. Org. Chem., 1993, 58, 904-912.

7 L. Dai, B. Winkler, L. Dong, L. Tong and W. H. A. Mau, Adv. Mater., 2001, 13, 915-925.

8 H. E. Katz, J. Mater. Chem., 1997, 7, 369-376.

9 M. Hiraoka, P. Fiorini, J. O'Callaghan, I. Yamashita, C. V. Hoof and M. Op de Beeck, Sens. Actuators, A, 2012, 177, 23-29.

10 K. Yan, Z.-X. Liu, X. Li, J. Chen, H. Chen and C.-Z. Li, Org. Chem. Front., 2018, 5, 2845.

11 D. Svirskis, J. Travas-Sejdic, A. Rodgers and S. Garg, J. Controlled Release, 2010, 146, 6-15.

12 N. Paradee and A. Sirivat, Polym. Int., 2013, 63, 106-113.

13 L. Ouyang, C. Musumeci, M. J. Jafari, T. Ederth and O. Inganäs, ACS Appl. Mater. Interfaces, 2015, 7, 1976419773.

14 A. Cho, S. Kim, S. Kim, W. Cho, C. Park, F. S. Kim and J. H. Kim, J. Polym. Sci., Part B: Polym. Phys., 2016, 54, 1530-1536.

15 K. Muro, M. Watanabe, T. Tamai, K. Yazawa and K. Matsukawa, RSC Adv., 2016, 6, 87147-87152.

16 C. Liu, F. Jiang, M. Huang, R. Yue, B. Lu, J. Xu and G. Liu, J. Electron. Mater., 2011, 40, 648-651.

17 S. Lim, S. H. Park, T. K. An, H. S. Lee and S. H. Kim, RSC Adv., 2015, 6, 2004-2010.

18 J. Ouyang, Q. Xu, C.-W. Chu, Y. Yang, G. Li and J. Shinar, Polymer, 2004, 45, 8443-8450.

19 J. Y. Oh, M. Shin, J. B. Lee, J. H. Ahn, H. K. Baik and U. Jeong, ACS Appl. Mater. Interfaces, 2014, 6, 6954-6961.

20 T. Horii, H. Hikawa, Y. Mochizuki and H. Okuzaki, Trans. Mater. Res. Soc. Jpn., 2012, 37, 515-518.

21 M. C. Lefebvre, Z. Qi and P. G. Pick up, J. Electrochem. Soc., 1999, 146, 2054-2058.

$22 \mathrm{~W}$. Wichiansee and A. Sirivat, Materials Science and Engineering C., 2008, 29, 78-84.

23 P. Chanthanont and A. Sirivat, Polym. Adv. Technol., 2013, 32, 21367. 
24 M. Lefebvre, Z. Qi, D. Rana and P. G. Pickup, J. Electrochem. Soc., 1999, 146, 2054-2058.

25 S. Khan and A. K. Narula, Eur. Polym. J., 2016, 81, 161-172.

26 Polypyrrole Stability and Coatings for Radar Absorbing Materials, 2004, http://www.dtic.mil/dtic/tr/fulltext/u2/ a436251.pdf.

27 Z. Fufang, Z. Baogai, S. Zhuoran, H. Yuanming and P. Chanxu, Key Eng. Mater., 2009, 407-408, 573-576.

28 N. Sangiorgi, L. Aversa, R. Tatti, R. Verucchi and A. Sanson, Opt. Mater., 2016, 64, 18-27.

29 T. Permpool, A. Sirivat and D. Aussawasathien, Polym. Int., 2014, 63, 2076-2083.

30 K. Phasuksom and A. Sirivat, Synth. Met., 2016, 219, 142-153.

31 C. Liang and H.-W. Su, Ind. Eng. Chem. Res., 2009, 48, 55585562.

32 C. Coletta, Z. Cui, A. Dazzi, J. M. Guigner, S. Neron, J.-L. Marignier and S. Remita, Radiat. Phys. Chem., 2016, 126, 21-31.

33 N. D. Koromilas, G. C. Lainioti, E. K. Oikonomou, G. Bokias and J. K. Kallitsis, Eur. Polym. J., 2014, 54, 39-51.

34 E. G. Langford, K. D. Shaughnessy, T. C. Devore, D. Lawrence and C. Constantin, MRS Adv., 2016, 1, 465-469.

35 C. Sriprachuabwong, C. Karuwan, A. Wisitsorrat, D. Phokharatkul, T. Lomas, P. Sritongkham and A. Tuantranont, J. Mater. Chem., 2012, 22, 5478-5485.

36 C. Lin, B. Fan, J. X. Zhang, X. Yang and H. Zhang, Desalin. Water Treat., 2015, 57, 21627-21733.

37 C. Yeon, G. Kim, J. W. Lim and S. J. Yun, RSC Adv., 2017, 7, 5888-5897.

38 K. Sukchol, S. Thongyai, P. Praserthdam and G. A. Sotzing, Synth. Met., 2013, 179, 10-17.

39 T.-R. Chou, S.-H. Chen, Y.-T. Chiang, T.-T. Chang, C.-W. Lin and C.-Y. Chao, Org. Electron., 2017, 48, 223-229.

40 T. G. Kim, S. R. Ha, H. Choi, K. Uh, U. Kundapur, S. Park, C. W. Lee, S. Lee, J. Kim and J.-M. Kim, ACS Appl. Mater. Interfaces, 2017, 9, 19231-19237.

41 C. Yeon, S. J. Yun, J. Kim and J. W. Lim, Adv. Electron. Mater., 2015, 1, 1500121.

42 Y. Xia and J. Ouyang, Macromolecules, 2009, 42, 4141-4147.

43 G. Zotti, S. Zecchin, G. Schiavon, F. Louwet, L. Groenendaal, X. Crispin, W. Osikowicz, W. Salaneck and M. Fahhman, Macromolecules, 2003, 36, 3337-3344.

44 M. Chen, K. Shafer-Peltier, S. J. Randtke and E. Peltier, Chem. Eng. J., 2018, 344, 155-164.

45 H. Park, S. H. Lee, F. S. Kim, H. H. Choi, I. W. Cheong and J. H. Kim, J. Mater. Chem. A, 2014, 2, 6532-6539.
46 L. Zhang, H. Deng, S. Liu, Q. Zhang, F. Chen and Q. Fu, RSC Adv., 2015, 5, 105592-105599.

47 A. B. Volynsky, A. Y. Stakheev, N. S. Telegina, V. G. Senin, L. M. Kustov and R. Wennirch, Spectrochim. Acta, Part B, 2001, 56, 1387-1396.

48 J. Zhao, S. Xu, K. Tschulik, R. G. Compton, M. Wei, D. O'Hare, D. G. Evans and X. Duan, Adv. Funct. Mater., 2015, 25, 2745-2753.

49 S. Fabiano, S. Braun, X. Liu, E. Weverberghs, P. Gerbaux, M. Fahlman, M. Berggren and X. Crispin, Adv. Mater., 2014, 26, 6000-6006.

50 L. Qie, W. Chen, X. Xiong, C. Hu, F. Zou, P. Hu and Y. Huang, Adv. Sci., 2015, 2, 1500195.

51 P. Tehrani, A. Kanciurzewska, X. Crispin, N. D. Robinson, M. Fahlman and M. Berggren, Solid State Ionics, 2007, 177, 3521-3527.

52 T.-C. Tsai, H.-C. Chang, C.-H. Chen and W.-T. Whang, Org. Electron., 2011, 12, 2159-2164.

53 B. Fan, X. Mei and J. Ouyang, Macromolecules, 2008, 41, 5971-5973.

54 S.-S. Yoon and D.-Y. Khang, J. Phys. Chem. C, 2016, 120, 29525-29532.

55 D. C. Sun and D. S. Sun, Mater. Chem. Phys., 2009, 118, 288292.

56 S. Maruthamuthu, J. Chandrasekaran, D. Manoharan, S. N. Karthick and H. J. Kim, J. Appl. Polym. Sci., 2016, 133, 43772.

57 D. Lensen, D. M. Vriezema and J. C. M. van Hest, Macromol. Biosci., 2008, 8, 991-1005.

58 S. Arunsawad, K. Srikulkit and S. Limpanart, J. Met., Mater. Miner., 2014, 24, 29-34.

59 B.-J. Kim, S.-G. Oh, M.-G. Han and S.-S. Im, Synth. Met., 2000, 122, 297-304.

60 H. Zhang and P. L. Dubin, J. Colloid Interface Sci., 1996, 186, 264-270.

61 E. Eren, G. Celik, A. Uygun, J. Tabačiarová and M. Omastová, Synth. Met., 2012, 162, 1451-1458.

62 D. Wang, S. Karato and Z. Jiang, Geophys. Res. Lett., 2013, 40, 2028-2032.

63 T. Tungkavet, N. Seetapan, D. Pattavarakorn and A. Sirivat, Mater. Sci. Eng., C, 2014, 46, 281-289.

64 Z. Qi and P. G. Pick up, Chem. Commun., 1998, 2299-2300.

65 T. Dai, X. Jiang, S. Hua, X. Wang and Y. Lu, Chem. Commun., 2008, 4279-4281. 